San Jose State University

SJSU ScholarWorks

Master's Theses

Master's Theses and Graduate Research

Summer 2019

\title{
Dynamics and Ecological Implications of the Ulva-Zostera Ecotone in Elkhorn Slough, California
}

María Vila Duplá

San Jose State University

Follow this and additional works at: https://scholarworks.sjsu.edu/etd_theses

\section{Recommended Citation}

Vila Duplá, María, "Dynamics and Ecological Implications of the Ulva-Zostera Ecotone in Elkhorn Slough, California" (2019). Master's Theses. 5048.

DOI: https://doi.org/10.31979/etd.ym6p-7dqg

https://scholarworks.sjsu.edu/etd_theses/5048

This Thesis is brought to you for free and open access by the Master's Theses and Graduate Research at SJSU ScholarWorks. It has been accepted for inclusion in Master's Theses by an authorized administrator of SJSU ScholarWorks. For more information, please contact scholarworks@sjsu.edu. 


\title{
DYNAMICS AND ECOLOGICAL IMPLICATIONS OF THE ULVA-ZOSTERA ECOTONE IN ELKHORN SLOUGH, CALIFORNIA
}

\author{
A Thesis \\ Presented to \\ The Faculty of Moss Landing Marine Laboratories \\ San José State University \\ In Partial Fulfillment \\ of the Requirements for the Degree of \\ Master of Science
}

by

María Vila Duplá

August 2019 
(C) 2019

María Vila Duplá

ALL RIGHTS RESERVED 
The Designated Thesis Committee Approves the Thesis Titled

DYNAMICS AND ECOLOGICAL IMPLICATIONS OF THE ULVA-ZOSTERA ECOTONE IN ELKHORN SLOUGH, CALIFORNIA

by

María Vila Duplá

APPROVED FOR THE DEPARTMENT OF MARINE SCIENCE

SAN JOSÉ STATE UNIVERSITY

August 2019

Michael H. Graham, Ph.D. Moss Landing Marine Laboratories

Ivano Aiello, Ph.D. Moss Landing Marine Laboratories

Scott L. Hamilton, Ph.D. Moss Landing Marine Laboratories 


\section{ABSTRACT \\ DYNAMICS AND ECOLOGICAL IMPLICATIONS OF THE ULVA-ZOSTERA ECOTONE IN ELKHORN SLOUGH, CALIFORNIA}

by María Vila Duplá

Ecotones are transitional areas between adjacent ecological communities that have unique ecological qualities defined by space and time scales, and by the interactions between adjacent systems. Ecotones play an essential role in supporting biologically diverse communities, and are sensitive indicators of global change. An Ulva-Zostera ecotone extends along the northern shore of Seal Bend in Elkhorn Slough, an estuary located in central California. Although previous studies have mentioned the presence of the Ulva-Zostera ecotone, this was the first study to focus on understanding its driving factors, spatiotemporal dynamics, and overall ecological implications. A combination of habitat monitoring, water quality assessments, sediment analyses, and recruitment and transplants experiments across the ecotone was used to describe the ecological characteristics of the system. Ecotone dynamics were driven by seasonality of Ulva spp. Distribution of Ulva spp. across the ecotone was limited by processes affecting its early developmental stages. The presence of Zostera marina initiated these mechanisms via modification of the environment and recruitment of grazers. Grazing was found to regulate macroalgal abundance, and specific grazer groups played an essential role in this. These results can be widely applied to guide future research efforts focusing on understanding and predicting habitat shifts and consequent ecosystem transformations. 


\section{ACKNOWLEDGMENTS}

My master's thesis is the result of a combined effort by a large number of individuals, without which my project would not have been possible. First, I want to thank Dr. Michael Graham, whose immense knowledge and work philosophy made him the best advisor I could ask for. I also want to thank my committee members, Dr. Ivano Aiello and Dr. Scott Hamilton, for sharing their knowledge and for their guidance in all stages of my thesis. I am very thankful to Dr. Kimberly Null and Holly Chiswell for helping me with nutrient analysis of my porewater and seawater samples. Sampling for my thesis implied many hours of small boat use that was possible thanks to the amazing Marine Operations crew. Although my international status prevented me from applying to most research grants, I received substantial funding from sources including SJSU, CSUMB's UROC program, Friends of MLML and other external scholarships.

I feel extremely lucky to have been part of the Moss Landing Marine Labs community, and I have to thank the MLML faculty, staff, shop guys and students, for all improving my grad school experience in one way or another. Special thanks to Katie Lage for employing me at the library during all three years and being the most understanding and caring supervisor one could ask for.

Being part of the BEERPIGS not only made me a better scientist, but also made me realize how much better of a scientist I can become. I want to thank all of my labmates, past and present, for sharing with me their passion for phycology and being supportive of one another from the beginning. In addition to the 
phycology lab, being part of the 2016 cohort is one of my points of pride. All 15 of us have navigated graduate school together, celebrated our personal and professional accomplishments and have always been there for one another.

Outside of the MLML community, I am very thankful to have had wonderful interns and volunteers that have joined me on my adventures in the mud and helped with different parts of my project. My roommates and friends in California have been my family away from home, my travel buddies and partners in crime. My biggest thank you goes to all the wonderful people that have been so kindly driving me around all over the place in the past three years. I could not have made it without them.

Last but not least, I want to thank my family and childhood friends. Thank you for always being enthusiastic and encouraging of my (often) crazy endeavors. This is all thanks to you, your unconditional support, and the certainty that no matter what the future holds, I always have a place to go back to. 


\section{TABLE OF CONTENTS}

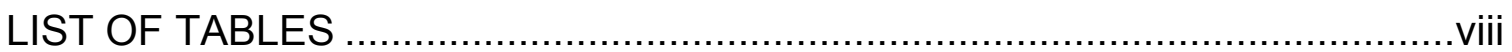

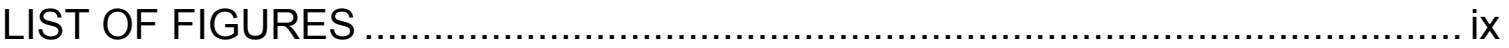

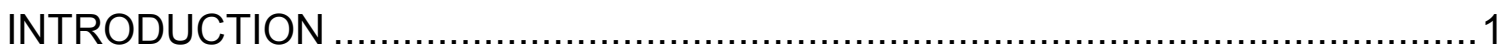

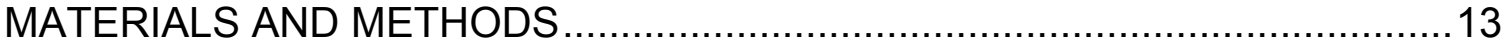

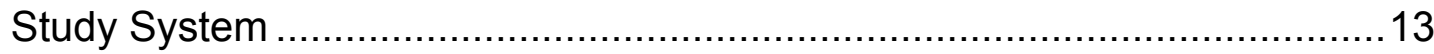

Sampling and Experimental Design ..................................................... 15

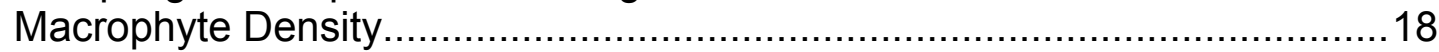

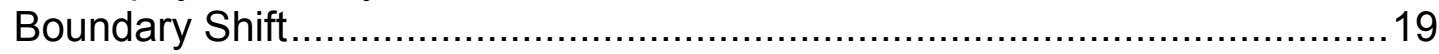

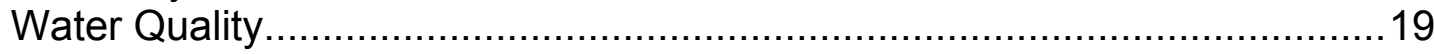

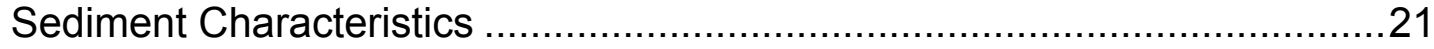

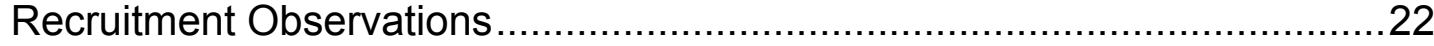

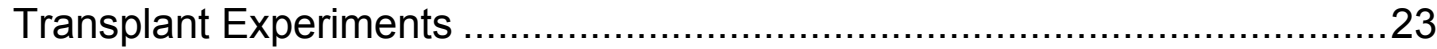

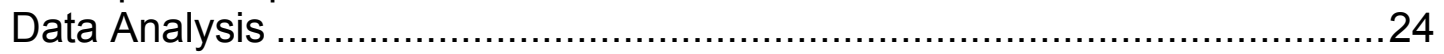

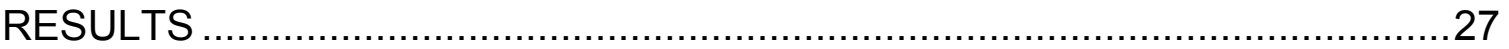

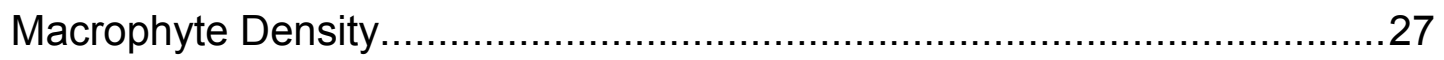

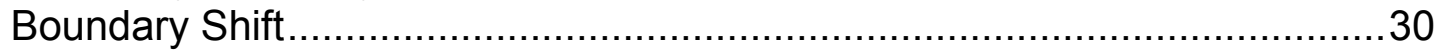

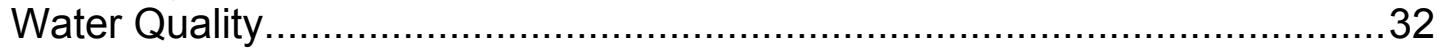

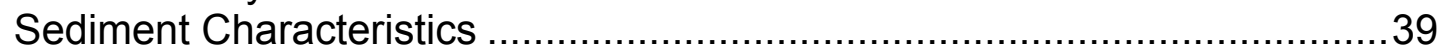

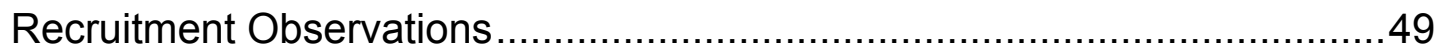

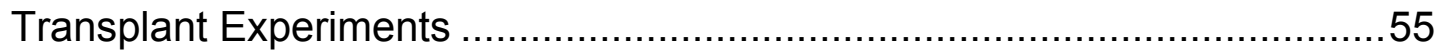

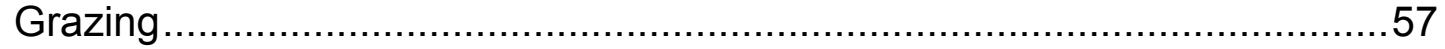

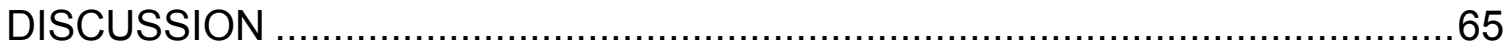

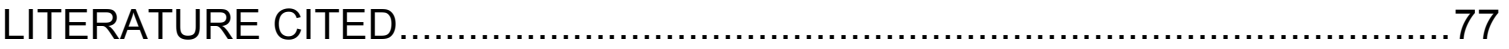




\section{LIST OF TABLES}

Table 1. Sampling dates, times, and tidal height of the ecotone boundary at time of sampling .

Table 2. Comparison of nutrient concentrations collected at Seal

Bend and a nearby sampling station .

Table 3. Summary of statistical analyses conducted.................................25-26 


\section{LIST OF FIGURES}

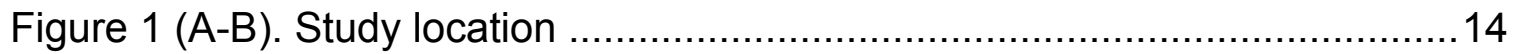

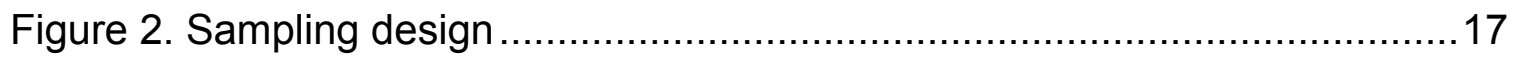

Figure 3 (A-B). Macrophyte abundance across the ecotone ..........................29

Figure 4. Seasonal changes in width of the ecotone boundary ........................31

Figure 5. Seasonal temperature fluctuations across the ecotone …...................33

Figure 6. Seasonal salinity fluctuations across the ecotone ............................34

Figure 7. Seasonal pH fluctuations across the ecotone …..............................36

Figure 8. Seasonal dissolved oxygen fluctuations across the ecotone

Figure 9. Porewater phosphate concentrations across the ecotone .................40

Figure 10. Porewater nitrate concentrations across the ecotone ......................42

Figure 11. Porewater ammonium concentrations across the ecotone

Figure 12 (A-B). Grain size across the ecotone ….........................................

Figure 13. Particle heterogeneity across the ecotone throughout the year.

Figure 14. Recruitment and transplant success across the ecotone throughout the year.

Figure 15. Percent cover of Ulva spp. on recruitment and transplant pipes 
Figure 16. Change in Ulva spp. biomass on recruitment pipes across the ecotone

Figure 17. Percent length of rope covered by Ulva spp. on transplants

Figure 18. Biomass of small mesograzers across the ecotone .58

Figure 19. Density of large mesograzers across the ecotone 60

Figure 20. Relative abundance of common large $(<1 \mathrm{~cm})$ mesograzers across the ecotone

Figure 21. Correlation between small grazer biomass and Ulva spp. percent cover on transplants across the ecotone .63

Figure 22. Correlation between large mesograzer density and U/va spp. percent cover on transplants across the ecotone 64

Figure 23. Regulating function of sea slugs in the eelgrass bed 64 


\section{INTRODUCTION}

Ecological research focuses on patterns and processes in variable systems and at numerous spatial and temporal scales (Allen and Starr 1982). Examining patterns in nature and developing theories based on the patterns observed is key to developing predictive theory for ecology (Levin 1992). Patterns imply repetition, and thus allow for prediction and modeling (MacArthur 1972). Observations of patterns or lack of patterns in the environment are the essential starting points for any ecological study, as they are the basis from which explanatory models about processes are developed (Underwood 2000). Ecological experiments attempt to link spatiotemporal patterns with ecological processes by characterizing patterns, developing hypotheses about the underlying processes, and evaluating them with experiments or models (Jeltsch et al. 1999, Fortin and Dale 2005). Areas of research that constantly make predictions from observable patterns include biogeography (e.g. Hillebrand 2004), conservation ecology (e.g. Paine 1980), and allometry (e.g. Kleiber 1947). Ecologists have become increasingly interested in describing and quantifying the underlying processes behind spatial patterns (Mclntire 2009). Fletcher and Fortin (2018) concluded that the first step in understanding any ecological process is to identify its spatial patterns. Spatial patterns are displayed by both physical and biological variables in nature (Levin 1992). While physical structure is sufficient to explain some spatial patterns, complex ecological interactions are often associated with patterns of species abundance and distribution (Underwood and 
Chapman 1996). The imprecision of biological processes and the possibility that multiple processes might be causing a single spatial pattern complicate pattern analysis (Mclntire 2009). Despite limitations, ecological patterns are used to inform theory, which in turn informs applied ecology (Chave 2013).

Ecotones, also known as habitat boundaries, are transitional structural elements within high diversity biological systems, both at the community and species level (Naiman et al. 1990). The "ecotone effect" refers to the pattern of increased species richness and abundance, and occurrence of unique species, at these system boundary regions (Odum 1953). There is also evidence that ecotones hold high biological diversity at the species level, which can translate into morphological and genetic diversity (Kark and van Rensburg 2006). This can occur because, according to the Gradient Model, sharp environmental gradients may lead to adaptive divergence and speciation, even if there is some gene flow across ecotones (Moritz 2001). Therefore, the presence of ecotones can be indicative of a system's greater ecological value compared to other systems (Risser 1993).

As transition regions between two or more ecological communities, the presence of ecotones is often explained by ecoclines, which are transition regions of physical properties (Attrill and Rundle 2002). The systems on either side of the ecotone tend to be characterized by different environmental factors that change across the ecotone boundary (Janauer and Kum 1996). Boundaries are often associated with increased beta-diversity (Kark 2013), although this may 
not be true for those that experience dramatic spatial and temporal fluctuations (van der Maarel 1976).

Transitional zones between habitats have traditionally been considered distinct from the habitats themselves (e.g. Livingston 1903, Clements 1905). They may act as semipermeable barriers that allow exchange of energy, nutrients, and propagules (Holland 2012). Changes in population or community structure and distribution at these boundaries between habitats are known as the "edge effect" (Forman and Godron 1986). For individual species, this implies a positive, negative or neutral change in abundance. Increased species abundances at the ecotone boundary are the most commonly reported pattern in the literature, and may be explained by spillover at the boundary, the ways in which edges enhance hábitat quality, or by influencing resource availability and distribution (Hansen et al. 1992).

Ecotones are often sorted into different levels depending on spatial scale. These levels are biome, landscape, patch, and population (Gosz 1993). This classification based on scale can be extremely helpful for identifying the range of constrains, patterns and processes associated with ecotones. While biome or landscape ecotones are probably constrained by climatic and topographic factors, transitional zones at finer scales are usually shaped by a larger number of factors, due to the fact that fine-scale variation is integrated at broad scales (Gosz 1993). Therefore, soil characteristics, interspecific interactions, physiological controls and population genetics have to be added to 
microclimatology and microtopography as possible constrains on community ecotones (Hansen et al. 1992). While some ecotones are generated by disturbance, others originate from edaphic boundaries due to climate, hydrology, or sediments (Hansen et al 1988). Natural ecotones tend to be irregularly shaped. If we place a transect across an ecotone, we expect to see increased spatial variation or increased patchiness right at the transition (Gosz 1993). Similarly, as one approaches ecotones, homogeneous patches decrease in size and the variety of patches increases (Delcourt and Delcourt 1992).

Ecotones are commonly formed in coastal areas and estuaries, where the distributions of many macrophyte foundation species overlap (Hauxwell et al. 2001). Foundation species are habitat-forming species that facilitate the presence of other organisms and communities by provisioning habitat and energy, and by modifying their abiotic environment in several ways (Graham et al. 2016). They provide various ecosystem services, including sediment stabilization and increased accretion, and reduction of hydrodynamic energy from currents and waves (Bos et al. 2007). Foundation species are also the main primary producers in coastal and estuarine ecosystems, and are responsible for maintaining diverse communities (Bouma et al. 2005). Marine communities are often structured by foundation species (Aquilino and Stachowicz 2012), and the resilience of communities highly depends on the nature and health of associated macrophytes (Olafsson 2017). 
As marine macrophytes, macroalgae and seagrasses are associated with key ecosystem services, such as carrying out photosynthesis and supplying organic matter, providing habitat and reducing physical stress to associated organisms. Macrophytes play a foundational role in marine ecosystems, and primary consumers depend on most macroalgal and seagrass taxa for fixed carbon and nutrients (Paine 2002). Many marine macrophytes act as ecosystem engineers that reduce hydrodynamic energy (Bouma et al. 2005). Aquatic vegetation with emergent structures that reach the water surface are often more effective in reducing wave height (Augustin et al. 2009). Much like coral reefs, sea lettuce mats and eelgrass meadows act as barriers that protect organisms living in them from strong waves and currents (Maxwell et al. 2015). The modification of hydrodynamic forces often results in increased sediment deposition, which has important implications for organisms associated with foundation species (Bos et al. 2007). Marine macrophytes also create shade and can prevent dessication of associated organisms in intertidal habitats (Maxwell et al. 2015). The ecosystem services provided by seagrass beds are among the highest for all aquatic ecosystems (Costanza et al. 1997), and include nutrient fixation, erosion prevention, and nursery function (Reusch and Hughes 2006). Eelgrass makes a perfect nursery habitat for commercially and ecologically important fish and invertebrate species, and serves as shelter from predators (Mackenzie Jr. 2005). Habitat and energy provisioning services, as well as the functional importance of macrophytes, vary depending on their size and distribution relative to the scale of 
the physical structure of their system (Dayton 1972). Thus, large and abundant macrophytes have a foundational role in regulating structure, diversity and production of coastal and wetland ecosystems (Graham 2004).

Estuarine ecosystems are unique in that they are diversity hotspots because of gradients in water properties caused by the input of both ocean water and fresh water into the system (McLusky and Elliot 2004). These gradients, combined with differing nutrient runoff in different sections of the estuary, increase diversity of seaweeds and aquatic plant species (Rykaczewski and Dunne 2010). Such patterns of habitat diversity can be observed in Elkhorn Slough, an upwelling-influenced estuary located in Monterey Bay, California $\left(36.8259^{\circ} \mathrm{N} 121.7569^{\circ} \mathrm{W}\right)$ (Elkhorn Slough Foundation 2002). The main sources of freshwater flowing into Elkhorn Slough are Carneros Creek and McClusky Slough to the north and Moro Cojo Slough to the south (Bassett 2010). Its main channel is approximately $11 \mathrm{~km}$ long and $3 \mathrm{~m}$ deep on average, with a tidal excursion of $5 \mathrm{~km}$, and tidal currents of $0.5-1 \mathrm{~m} / \mathrm{s}$ (Smith 1973). During the rainy season, nitrate concentrations are usually high in the estuary and can reach values of up to $450 \mu \mathrm{M}$, mainly due to agricultural runoff from nearby farms (Chapin et al. 2004). Conversely, land-based nitrate input is reduced during the dry season and nitrate concentrations are 0-20 $\mu \mathrm{M}$ (Chapin et al. 2004); however, upwelled ocean water remains an important source of nitrate entering the estuary, since it accounts for $80-90 \%$ of the nitrogen load during the dry 
season (Chapin et al. 2004). These seasonal and spatial characteristics have an influence on the biological components of the estuary.

The dominant macrophytes in the Elkhorn Slough system are Zostera marina and two species within the Ulva genus: U. intestinalis and U. lactuca (Hughes 2016). These macrophytes overlap in several locations throughout the main channel, forming ecotones that vary in scale. The largest Ulva-Zostera ecotone extends for $400 \mathrm{~m}$ along the northern shore of Seal Bend, 1-2 km from the mouth of Elkhorn Slough (Fig. 1A). The eelgrass and macroalgal populations vary in width, and the boundary of the Ulva-Zostera ecotone is irregularly shaped and is visible in aerial images and during low tide (Fig. 1B). The ecotone boundary is home to a wide variety of epigrazers, some of which are very important in the Elkhorn Slough system (Grant 2009). In many systems, macroalgal biomass is directly associated with decreased eelgrass biomass, showing the potential for negative interactions between macrophytes (Hessing-Lewis 2011, Hughes et al. 2016). There are various macrophyte species in the estuary, which leads to a variety of habitats found in a relatively small area.

Ulva is a fast-growing green alga that forms mats used by invertebrates as attachment surfaces (Thiel and Fraser 2016). These mats block sunlight and reduce thermal stress on mesograzers and the habitat they provide boosts recruitment of invertebrates, like amphipod crustaceans and polychaete worms (Lyons et al. 2014). High temperatures and storms have been reported as the major threats affecting sea lettuce populations (Filbee-Dexter \& Scheibling 2012). 
Ulva shows little response to low $\mathrm{pH}$ levels and $\mathrm{CO}_{2}$ increases, unless they are coupled with temperature, salinity, and high nutrients (Connell and Russell 2010). Other factors limiting the distributional range of Ulva are possibly grazing and competition with other aquatic plants (Green and Fong 2016). Blooms of Ulva and other macroalgal species caused by eutrophication can have severe effects on estuarine environments (Mackenzie 2005). Sea lettuce overgrows and causes the death of aquatic plants and mollusk species, occupying significant portions of shallow estuarine water and restricting feeding zones of birds, fish and invertebrates (Raffaeli et al. 1989). In addition to being an opportunistic species, the spread of Ulva mats alters water chemistry by adding and removing nutrients from the system throughout its life cycle (Teichberg 2010). One of the most important ecosystem services Ulva spp. provides is the removal of phosphates and nitrates as they grow in the spring and consequently release nutrients when they disintegrate in the fall (Deegan et al. 2002). Ulva blooms can also have indirect effects on higher trophic levels and often disrupt ecosystem dynamics (Lyons 2014). The two commonly used conservation approaches to buffer these changes triggered by Ulva spp. are preventing nutrient runoff at their watershed sources and removing macroalgal biomass by either harvesting or increased flushing (Valiela et al. 1997).

Zostera marina is a perennial seagrass found in North America and Eurasia that provides critical services such as nutrient recycling, sediment stabilization, and carbon sequestration (Bostrom and Bonsdorff 2000). It also provides an 
important nursery habitat commonly used as an indicator of ecological quality (Short et al. 2006). The seagrass is often carbon-limited, and fairly sensitive to light, nutrients, and sediment variability (Leoni et al. 2008). The effects of decreased light are a reduction in both shoot morphology and shoot density, and growth rate (Moore and Wetzel 2000). High temperatures can slow or disrupt ontogenetic transitions, affecting flowering and seed germination (Waycott 2007). Degraded water quality due to anthropogenic climate change is the main cause of disappearance of at least $29 \%$ of the known global coverage of seagrass habitats (Waycott et al. 2009). Species that seek refuge in eelgrass beds include crabs, scallops and juvenile salmon (Boström et al. 2014).

Macrophytes can also determine topographic complexity and trophic interactions within an ecosystem (Angelini 2011). However, the abiotic conditions driving ecoclines that favor a particular habitat provider at certain levels are poorly understood. Therefore, determining what factors might be responsible for the spatial variability in macrophyte relative abundance at the ecotone level is an important research priority (Bostrom et al. 2017). Among the spatially variable abiotic factors that might influence ecotone dynamics are physical properties of the water such as temperature, salinity, $\mathrm{pH}$, dissolved oxygen, desiccation, Photosynthetic Active Radiation (PAR) and nutrient concentrations (Janauer 2001). Photosynthetic Active Radiation refers to the amount of light (400-700nm) that photosynthetic organisms can utilize for photosynthesis (Carruthers et al. 2001). In recent studies, Photosynthetic Active Radiation (PAR) has been 
suggested to be the main factor responsible for the distribution of Zostera marina in coastal habitats (Gao et al. 2011). Stevenson et al. (1996) concluded that salinity and porewater nutrients appear to have a greater effect on the spatial distribution of macrophytes than temperature or $\mathrm{pH}$. Other field observations and laboratory experiments have demonstrated that light, temperature and nutrient supply are key environmental factors that stimulate germination of Ulva spp. and facilitate algal blooms that disfavor Zostera (Worm et al. 1999). On the other hand, temperature and light levels are most likely responsible for most of the seasonal variability (Campbell et al. 2014). However, there is evidence suggesting that eelgrass is resilient to high fluctuations in macroalgal biomass and production through time, and is more affected by local climate and nutrient loading in estuaries (Hessing-Lewis 2011).

Piriou and Duval (1990) reported termination of Ulva growth at the beginning of the summer, with increased light intensity and longer photoperiods, hinting a strong sensitivity of Ulva spp. to light. It seems clear that when sufficient light is available, nutrient availability and optimal temperature ranges lead to macroalgal proliferation (Olafsson 2017). Interception of light by epiphytic and filamentous algal species like Ulva spp. on leaf surfaces causes a decline in submerged aquatic vegetation (Twilley 1985). Drift algae can originate from hard substrata surrounding eelgrass beds and its spatial distribution within the ecotone might be associated with eelgrass species composition and zonal distribution (Bell and Hall 1997). Interspecific resource competition has to be added to environmental 
variables as a biotic factor to take into consideration at the scale of the ecotone boundary (Green and Fong 2015).

Proliferation of bloom-forming algae like Ulva spp. associated with seagrass population decline is common in eutrophic estuaries in the North Temperate Zone and has become an increasing problem worldwide (Valiela et al. 1997). High frequencies of algal bloom occurrence are mostly attributed to eutrophication, and increased availability of nutrients leads to shifts of macrophytes (Raffaeli et al. 1998). Availability of nitrogen and phosphorus originating from land, via either anthropogenic sewage or fertilization runoff, is possibly a major factor influencing composition and dynamism of the UlvaZostera ecotone (Wang et al. 2012). While nitrogen supply affects maximum seasonal rates of macroalgal growth in coastal and estuarine ecosystems (Lapointe et al. 1992), Valiela et al. (1997) found that phosphorus can be the limiting factor for macrophyte production in carbonate-rich waters for certain taxa.

Sediment composition has also been reported to affect gametophyte development (Devinny and Volse 1978), spore attachment (Lilly et al. 1953), and distribution (Ebling et al. 1960) of macroalgal species. Among the sediment characteristics associated with macrophyte ecology are grain size and particle heterogeneity (Schiel et al. 2019), and concentration of organic matter in the sediment (Silveira 2015). Schiel et. al (2019) observed important changes in community structure, such as shifts in dominant macrophyte species, as a response to changes in sediment type. Sandy sediments are throught to support 
poor macrophyte growth, possibly due to their low organic matter content (Barko and Smat 1986). Effects of sedimentation on macroalgae appear to be speciesspecific, and dependent on reproductive strategies (Eriksson and Johansson 2005).

While previous studies have mentioned the presence of the Ulva-Zostera ecotone at Seal Bend (e.g. Grant 2009, Hughes 2016), it was not the main focus of these studies. Aerial images can be used to estimate ecotone dynamics at large spatiotemporal scales, but small-scale changes and processes underlying the patterns observed have not been examined. Little attention has been given to determining what are the factors limiting the distribution of Ulva spp., and their relative importance in this particular system. This was the first study to focus on understanding its driving factors, spatiotemporal dynamics, and overall ecological implications of the ecotone.

The purpose of this project is to shed some light on the biological and physical processes and patterns associated with the Ulva-Zostera ecotone in Elkhorn Slough, as well as describe changes in population ecology of Ulva spp. across the macrophyte-driven ecotone. I focused on identifying the main factors correlated with ecotone dynamics, and quantifying the relative importance of each one of the factors limiting the distribution of Ulva spp. My approach was to monitor water quality, macrophyte density, and sediment characteristics, and conduct recruitment and transplant experiments. The ultimate goal was to further 
understand the nature and dynamics of ecotonal zones in estuarine environments, from an ecological perspective.

\section{MATERIALS AND METHODS}

\section{Study System}

The study location was the Ulva-Zostera ecotone found in the main channel of Elkhorn Slough, throughout Seal Bend (Figure 1). Seal Bend is $500 \mathrm{~m}$ long S$\mathrm{E}$ and $500 \mathrm{~m}$ wide $\mathrm{W}-\mathrm{E}$, and located approximately $1-2 \mathrm{~km}$ away from the mouth of the estuary. Elkhorn Slough is home to many ecologically and commercially important species such as flat fishes, harbor seals, leopard sharks, and Southern sea otters (Wasson et al. 2002). Common taxa that associate with the UlvaZostera ecotone include juvenile fishes and invertebrates like sea slugs, isopods, crabs, and snails (Grant 2009). 

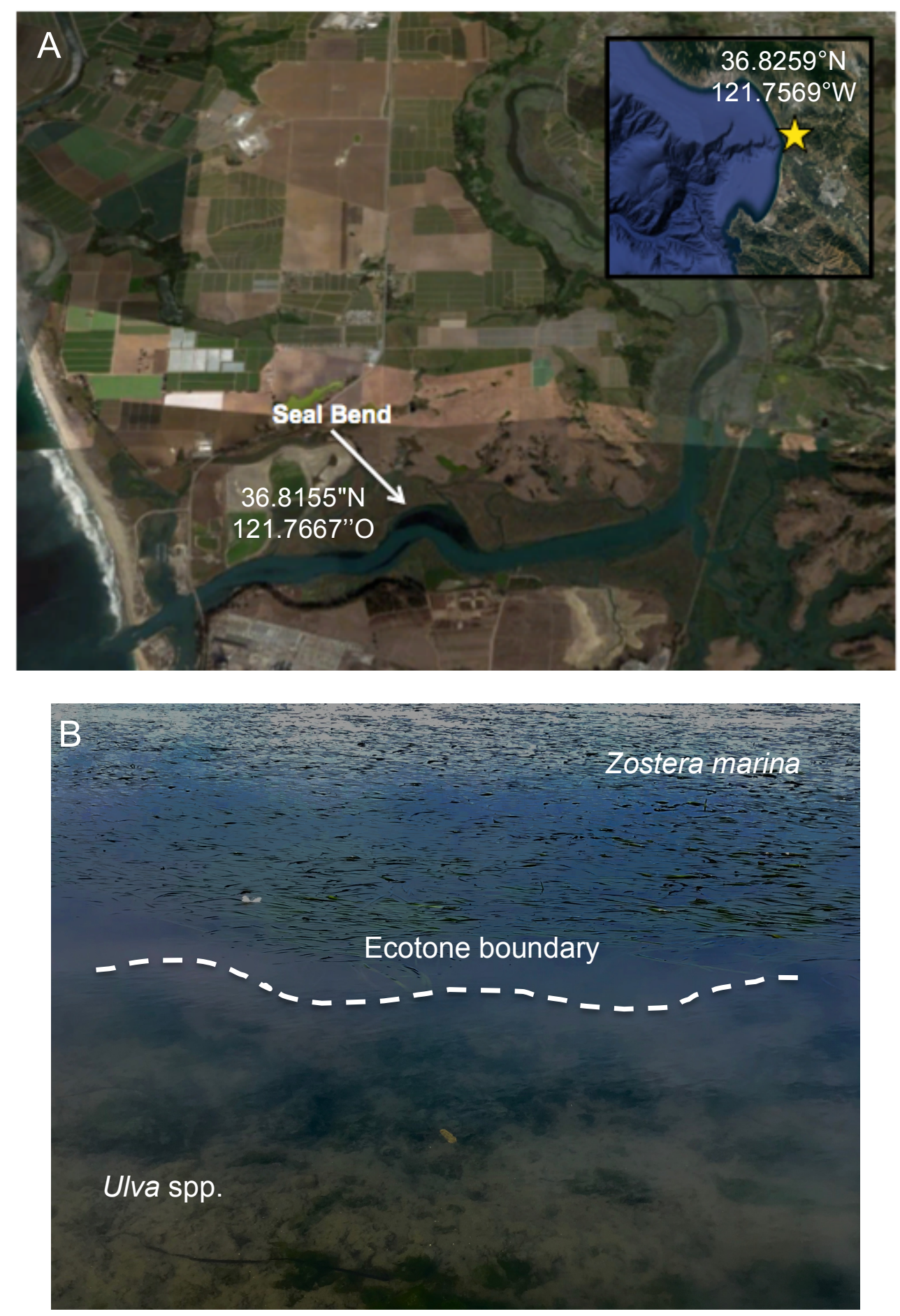

Figure 1. Study location. (A) Map of Elkhorn Slough and Seal Bend. (B) Closeup photograph of the Ulva-Zostera ecotone boundary at Seal Bend. 
At Seal Bend, I specifically addressed the following objectives:

1. Monitor spatial and seasonal changes in macrophyte density across the Ulva-Zostera ecotone.

2. Quantify seasonal dynamics and shifting of the ecotone boundary.

3. Determine whether abiotic factors including water quality, porewater nutrients, and sediment type influence the distribution of Ulva spp. across the ecotone.

4. Examine whether competition for light and space limits the distribution of Ulva spp. across the ecotone.

5. Evaluate whether grazing is a key factor limiting the distribution of Ulva spp. across the ecotone.

\section{Sampling and Experimental Design}

The study site included a total of 5 permanent transects to account for the spatial variability of the ecotone (Figure 2). All transects were $30 \mathrm{~m}$ in length, and randomly placed across the transitional zone perpendicular to the shore, with tidal height ranging between $-0.1 \mathrm{~m}$ and $0.5 \mathrm{~m}$ at the beginning of each sampling period (Table 1). All measurements and samples were collected right at the boundary (mark zero on transect) and at various distances from it (marks $5 \mathrm{~m}, 10$ $\mathrm{m}$, and $15 \mathrm{~m}$ on the transect) in both directions, into the Ulva spp. zone and the Zostera bed (Figure 2). This sampling design is common in ecotone research, as it allows for the description of patterns based on spatial variation of biological and physical parameters (Janauer and Kum 1996). Experiments and observations 
were repeated across one additional transect placed outside of the eelgrass bed, but with the same depth distribution, to be used as a control. The boundary at the control was initially set as a function of tidal height, using the average tidal height at the boundary mark on the other five transects as a reference. Sampling was repeated every two months for thirteen months, for a total of seven sampling periods, to assess seasonal variability. 

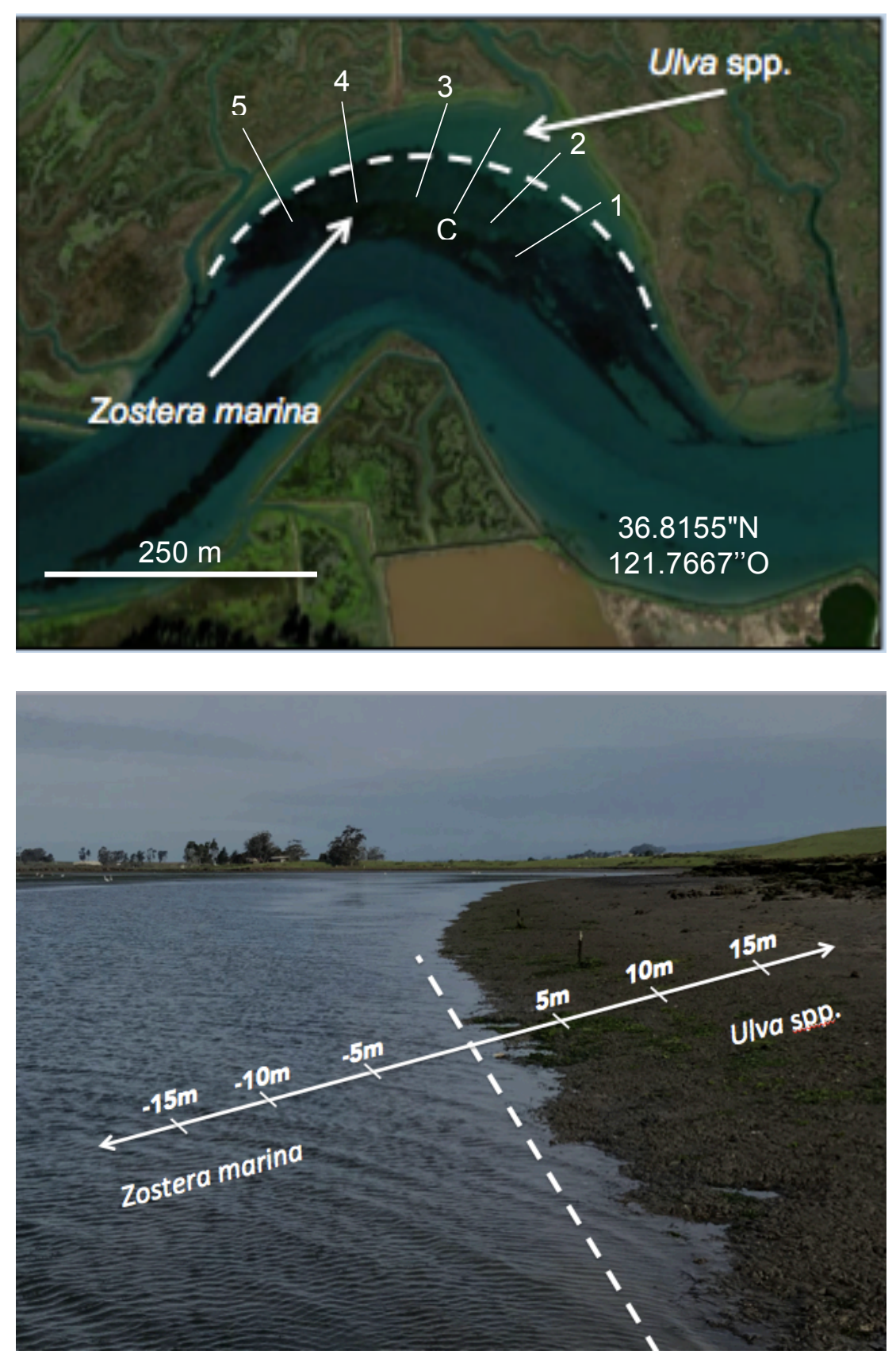

Figure 2. Sampling design. Location of transects across the Ulva-Zostera ecotone for measurements, collections, and experiments. The darker green area is the eelgrass bed, while the lighter green area leading to the marsh is the macroalgal-covered mud. The dashed line is the ecotone boundary, while the continuous lines indicate how transects were placed across the Ulva-Zostera ecotone. 
Table 1. Sampling dates, times, and tidal height of the ecotone boundary at time of sampling.

\begin{tabular}{|c|c|c|c|}
\hline Date & Time & $\begin{array}{c}\text { Low/High } \\
\text { tide }\end{array}$ & Tidal height $(\mathbf{m})$ \\
\hline 5/12/18 & $3-5: 30$ PM & Low & 0.2 \\
\hline $5 / 13 / 18$ & $3: 30-5$ PM & Low & 0.3 \\
\hline $5 / 26 / 18$ & $3: 00-3: 45$ PM & Low & 0.3 \\
\hline $6 / 24 / 19$ & $2: 15-4: 30$ PM & Low & 0.5 \\
\hline $7 / 5 / 18$ & $10: 15-11: 30$ AM & Low & 0.2 \\
\hline 9/8/18 & $3: 45-6: 00$ PM & Low & 0.4 \\
\hline 9/22/18 & $3: 30-4: 30$ PM & Low & 0.5 \\
\hline $11 / 3 / 18$ & $2: 15-3: 45$ PM & Low & 0.4 \\
\hline $11 / 4 / 18$ & $2: 00-4: 15$ PM & Low & 0.2 \\
\hline $11 / 17 / 19$ & $1: 30-2: 30$ PM & Low & 0.4 \\
\hline $1 / 27 / 19$ & $10: 30 A M-12: 45$ PM & Low & 0.4 \\
\hline $1 / 28 / 19$ & $11: 30 A M-2: 15$ PM & Low & 0.2 \\
\hline $2 / 11 / 19$ & $9: 15-10: 45$ AM & Low & 0.5 \\
\hline $3 / 11 / 19$ & $8: 45-11: 45$ AM & Low & 0.3 \\
\hline $3 / 12 / 19$ & $9: 45 A M-12: 30$ PM & Low & 0.2 \\
\hline $3 / 25 / 19$ & $9: 00-10: 30$ AM & Low & 0 \\
\hline $4 / 24 / 19$ & $9: 30-1: 00$ PM & Low & -0.1 \\
\hline $5 / 4 / 19$ & $4: 30-5: 30$ PM & Low & 0.4 \\
\hline
\end{tabular}

\section{Macrophyte Density}

Density of Ulva spp. was estimated as percent cover. At every $5 \mathrm{~m}$ mark on the transects, $0.5 \mathrm{~m}^{2}$ quadrats were placed and photographed using a GoPro Hero 2 with a $14 \mathrm{~mm}$ focal longitude at a $170^{\circ}$ angle. These photographs were taken from a distance of $0.75 \mathrm{~m}$ and later analyzed using ImageJ software to obtain estimates of Ulva spp. percent cover. In ImageJ, Images were 
transformed using the binary function, and the threshold tool was used to adjust the pixel values to be highlighted and measured. Density of Zostera marina was estimated by counting the number of eelgrass shoots within the same $0.5 \mathrm{~m}^{2}$ quadrats used to estimate percent cover of Ulva spp., placed along each transect across the ecotone.

\section{Boundary Shift}

At the beginning of the study, the ecotone boundary (mark zero on the transects) was established at the mid-point between the edge of the eelgrass bed and the nearest patch of Ulva spp. on each transect. The distance between this boundary and the edge of the eelgrass bed was calculated from the photographs taken for macrophyte density estimates. Similarly, the distance between the ecotone boundary and the edge of the nearest Ulva spp. patch on each sampling date was calculated. These values were used to estimate seasonal shift and variation in width of the boundary.

Water Quality

Changes in water quality were estimated using a multi-parameter recording instrument (YSI Professional Plus Multiparameter Meter) to take in situ measurements of temperature, salinity, $\mathrm{pH}$, and dissolved oxygen across the ecotone. These measurements were taken during low tide, in the submerged section of the ecotone along the six transects, which included the marks at the boundary $(0 \mathrm{~m})$ and 5-15 $\mathrm{m}$ into the eelgrass bed, every two months. Additionally, surface water samples were collected in three arbitrary locations 
within the eelgrass bed from May 2018 to November 2018, and analyzed for nutrient concentrations. Since the average monthly values obtained did not differ significantly from those collected at a nearby sampling station (Table 2), the data were only used for reference.

Table 2. Comparison of nutrient concentrations collected at Seal Bend and a nearby sampling station. These data show the mean concentration values of surface water samples collected at three arbitrary locations within the eelgrass bed at Seal Bend from May to November 2018.

\begin{tabular}{|c|c|c|c|}
\hline Month & Nutrient & Seal Bend $(\boldsymbol{\mu M})$ & Sampling Station $(\boldsymbol{\mu M})$ \\
\hline May 2018 & Phosphate & 0.571 & 0.421 \\
\hline May 2018 & Nitrate & 1.584 & 3.194 \\
\hline May 2018 & Ammonium & 10.951 & 9.982 \\
\hline July 2018 & Phosphate & 0.213 & 0.210 \\
\hline July 2018 & Nitrate & 1.336 & 2.083 \\
\hline July 2018 & Ammonium & 0.996 & 1.174 \\
\hline Sep 2018 & Phosphate & 0.289 & 0.316 \\
\hline Sep 2018 & Nitrate & 4.565 & 5.278 \\
\hline Sep 2018 & Ammonium & 3.971 & 4.697 \\
\hline Nov 2018 & Phosphate & 0.420 & 0.211 \\
\hline Nov 2018 & Nitrate & 4.528 & 5.000 \\
\hline Nov 2018 & Ammonium & 12.094 & 7.046 \\
\hline
\end{tabular}




\section{Sediment Characteristics}

Porewater Nutrients: Push cores (5 $\mathrm{cm}$ diameter) were used to take sediment samples. The cores were sliced into two sections, transferred to $50 \mathrm{~mL}$ Falcon tubes, and transported to the laboratory in a cooler. In the laboratory, as much volume of porewater as possible was extracted from the Falcon tubes by decantation after centrifuging them for five minutes at 5000rpm, following recommendations of Carignan et al. (1985) for porewater sampling techniques. Porewater samples were filtered through $0.7 \mu \mathrm{m}$ Whatman glass fiber filters into acid-cleaned Falcon tubes and frozen until analysis. Preparation for analysis included thawing the samples and diluting them with Milli-Q water by 1:20 or $1: 15$, depending on the volume of sample available. Nutrient concentrations were measured on a Lachat QuickChem 8000 series autoanalyzer, yielding values for phosphate, ammonium, nitrite, and nitrate/nitrite concentrations.

Grain-Size Analysis: After extracting the porewater, sediment samples were used to test for differences in particle heterogeneity and grain size using a Beckman Coulter Laser Particle Sizer LS1230, an optical instrument that uses the Mie principle of light diffraction to measure particles between $0.04 \mu \mathrm{m}$ and $2000 \mu \mathrm{m}$. Before doing grain size analysis, a small amount of each sample was transferred to a beaker. Approximately $7 \mathrm{~mL}$ of $30 \%$ hydrogen peroxide was added and left to react for 48 hours to break down the organic matter in the sample. The amount of sample that needed to be added to the aqueous module attached to the Laser Particle Sizer was initially determined by running a few 
tests to find the obscuration range in which grain size measurements were repeatable. All samples were run at $12-15 \%$ obscuration and sonicated for $5-15$ seconds when needed to insure the full disaggregation of the particles. Mean, median, mode and standard deviation of grain size were calculated using the proprietary Beckman Coulter software, and the standard deviation was used as an indicator of particle heterogeneity within each sample (McCave and Syvitski 1991).

\section{Recruitment Observations}

Artificial settlement surfaces were designed to determine if the distribution of Ulva spp. was driven by its inability to recruit to the eelgrass bed due to light availability or differences in sediment characteristics. The settlement surfaces were $0.75 \mathrm{~m}$ portions of nylon rope attached to $1 \mathrm{~m}$ PVC pipes that were vertically inserted in the mud. Following the general experimental setup, the PVC pipes were placed at seven different marks along each of the five $30 \mathrm{~m}$ transects randomly distributed across the ecotone (Fig. 2). The lines of rope were checked two weeks later, and the presence or absence of Ulva spp. was recorded at each mark. For the ropes with successful recruitment, the percentage of the rope surface that was covered with algae was noted, as was the distance between the point of attachment of the rope at the top of the PVC pipe and the section of the rope where Ulva spp. stopped recruiting. After taking all measurements, the rope lines were detached from the pipes, put in labeled polyethylene bags, and transported back to the laboratory. The seaweed was scrapped off the rope, 
separated from other plants and detritus, bubbled when needed, rinsed, dried at $27^{\circ} \mathrm{C}$ for 48 hours, and weighed on an analytical scale with $0.1 \mathrm{mg}$ resolution to obtain estimates of Ulva spp. biomass.

\section{Transplant Experiments}

Transplant experiments were conducted to determine whether the distribution of Ulva spp. across the ecotone was a result of processes affecting adult individuals or early developmental stages. PVC pipes with attached nylon rope (same as recruitment experiments) were previously placed $15 \mathrm{~m}$ into the Ulva spp. side of the ecotone to allow UIva spp. to recruit to them. Each time the PVC pipes were set up for transplanting, rope line portions with 100\% Ulva spp. cover were selected and attached to the PVC pipes that were placed across the ecotone. These served as transplants that were checked after two weeks and transplant results were recorded as "successful" or "failed" to determine whether adult Ulva spp. could survive at each mark on the transect. For lines with transplant success, the percentage of the rope surface that was covered with algae was recorded, and the distance between the point of attachment of the rope at the top of the PVC pipe and the section of the rope where Ulva spp. was no longer present was also recorded. The presence or absence of mesograzers on the ropes was recorded, and the number of large mesograzers $(>1 \mathrm{~cm})$ within each of four groups (i.e. sea slugs, isopods, crabs, and sea snails) was counted. After taking all measurements, rope lines were detached from the pipes, placed in labeled polyethylene bags, and transported back to the laboratory. To obtain 
small $(<1 \mathrm{~cm})$ mesograzer biomass estimates, ropes were scrapped; mesograzers were separated from the seaweed, rinsed, dried in an oven at $27^{\circ} \mathrm{C}$, and weighed on a scale with a $10 \mathrm{mg}$ resolution.

\section{Data Analysis}

All data analysis was done using JMP Pro 13 statistical software. Table 3 shows the types of data produced, and the statistical variables and tests that were conducted on these data based on the main questions and experimental design. To test for differences between mean values of dependent variables at the different marks along transects, two different types of statistical tests were used: two-way analysis of variance (ANOVA) for normally distributed data, and Kruskal-Wallis test for non-normally distributed data. Generalized linear models (GLM) were used to test for associations between binomial dependent variables and distance from the ecotone throughout the year. Correlations between continuous variables were tested using the correlation test that best fit the data in each case. 
Table 3. Summary of statistical analyses conducted.

\begin{tabular}{|c|c|c|c|c|}
\hline Ohiective & Data nrodured & \multicolumn{2}{|c|}{ Variables } & \\
\hline Uojective & Data proaucea & Independent & Dependent & Statistical I lest \\
\hline \multirow[t]{2}{*}{1} & \multirow{2}{*}{$\begin{array}{l}\text { Macrophyte } \\
\text { density }\end{array}$} & $\begin{array}{l}\text { Distance from ecotone } \\
\text { Month }\end{array}$ & $\begin{array}{l}\text { Zostera density } \\
\text { Ulva \% cover }\end{array}$ & $\begin{array}{c}\text { Two-Way ANOVA \& } \\
\text { One-Way ANOVA }\end{array}$ \\
\hline & & Ulva \% cover & Zostera density & Nonlinear Regression \\
\hline 2 & Boundary width & Month & $\begin{array}{c}\text { Distance between } \\
\text { macrophytes \& boundary }\end{array}$ & Kruskal-Wallis \\
\hline \multirow{4}{*}{3} & $\begin{array}{c}\text { YSI } \\
\text { measurements }\end{array}$ & \multirow{4}{*}{$\begin{array}{c}\text { Distance from ecotone } \\
\text { Month }\end{array}$} & $\begin{array}{c}\text { Temperature } \\
\text { Salinity } \\
\mathrm{pH} \\
\text { Dissolved oxygen }\end{array}$ & \multirow{4}{*}{$\begin{array}{c}\text { Two-Way ANOVA } \\
\& \\
\text { One-Way ANOVA / } \\
\text { Kruskal-Wallis }\end{array}$} \\
\hline & $\begin{array}{c}\text { Nutrient } \\
\text { concentrations }\end{array}$ & & $\begin{array}{l}\text { Phosphate } \\
\text { Nitrate } \\
\text { Ammonium }\end{array}$ & \\
\hline & \multirow{2}{*}{$\begin{array}{c}\text { Sediment } \\
\text { characteristics }\end{array}$} & & Mean grain size & \\
\hline & & & Particle heterogeneity & \\
\hline \multirow{6}{*}{4} & $\begin{array}{l}\text { Ulva recruitment } \\
\text { success }\end{array}$ & \multirow{6}{*}{$\begin{array}{c}\text { Distance from ecotone } \\
\text { Month }\end{array}$} & $\begin{array}{c}\text { Presence/absence } \\
\text { of Ulva }\end{array}$ & $\begin{array}{l}\text { Generalized Linear } \\
\text { Model (Binomial) }\end{array}$ \\
\hline & $\begin{array}{l}\text { Ulva \% cover on } \\
\text { recruitment pipes }\end{array}$ & & Ulva \% cover & \multirow{2}{*}{$\begin{array}{c}\text { Two-Way ANOVA \& } \\
\text { One-Way ANOVA / } \\
\text { Kruskal-Wallis }\end{array}$} \\
\hline & Ulva biomass & & Ulva biomass & \\
\hline & $\begin{array}{c}\text { Transplant } \\
\text { success }\end{array}$ & & $\begin{array}{c}\text { Presence/absence } \\
\text { of Ulva }\end{array}$ & $\begin{array}{l}\text { Generalized Linear } \\
\text { Model (Binomial) }\end{array}$ \\
\hline & \multirow{2}{*}{$\begin{array}{l}\text { Ulva \% cover on } \\
\text { transplants } \\
\text { Maximum length } \\
\text { of Ulva cover }\end{array}$} & & Ulva \% cover & \multirow[b]{2}{*}{$\begin{array}{l}\text { Two-Way } \\
\text { ANOVA }\end{array}$} \\
\hline & & & Length of Ulva growth & \\
\hline
\end{tabular}




\begin{tabular}{|c|c|c|c|c|}
\hline 4 & $\begin{array}{l}\text { Recruitment vs } \\
\text { transplant } \\
\text { success }\end{array}$ & Recruitment success & Transplant success & $\begin{array}{l}\text { Fisher's } \\
\text { Exact Test }\end{array}$ \\
\hline \multirow{4}{*}{5} & Grazer & \multirow[b]{3}{*}{$\begin{array}{l}\text { Distance from ecotone } \\
\text { Month }\end{array}$} & Small grazer biomass & \multirow[b]{3}{*}{$\begin{array}{l}\text { Two-Way } \\
\text { ANOVA }\end{array}$} \\
\hline & abundance & & Large grazer counts & \\
\hline & $\begin{array}{c}\text { Relative } \\
\text { abundance of } \\
\text { grazer groups }\end{array}$ & & $\begin{array}{l}\% \text { of slugs } \\
\% \text { of isopods } \\
\% \text { of crabs } \\
\% \text { of snails }\end{array}$ & \\
\hline & $\begin{array}{c}\text { Ulva abundance } \\
\text { vs grazer } \\
\text { abundance }\end{array}$ & $\begin{array}{l}\text { Ulva \% cover on } \\
\text { transplants }\end{array}$ & $\begin{array}{c}\text { Slug counts } \\
\text { Isopod counts } \\
\text { Crab counts } \\
\text { Snail counts } \\
\text { Small grazer biomass }\end{array}$ & Linear Regression \\
\hline
\end{tabular}




\section{RESULTS}

\section{Macrophyte Density}

As expected, abundance of Ulva spp. across the ecotone and across seasons (Fig. 3A; two-way ANOVA, Distance: $F_{6,196}=53.5$, $p<0.0001$, Season: $F_{6,196}=9.56$, $p<0.0001$, Distance $x$ Season: $\left.F_{36,196}=53.5, p=0.0242\right)$. Ulva spp. cover increased with increasing distance away from the Zostera bed and the ecotone boundary. The highest macroalgal abundance was observed $15 \mathrm{~m}$ away from the boundary into the Ulva spp. zone. Percent cover of Ulva spp. was very low in quadrats placed at the boundary, and insignificant at every mark within the eelgrass bed. Overall Ulva spp. abundance differed significantly among sampling periods, peaking in the spring and summer relative to the fall and winter months. Ulva spp. abundance patterns across the ecotone were not consistent throughout the year, with stronger increase in abundance with increasing distance from the boundary in the spring than other seasons. Abundance of Ulva spp. varied significantly across the transect used as a control, outside of the eelgrass bed (Fig. 3A; one-way ANOVA, $F_{6,42}=2.75, p=0.0239$ ). Macroalgal cover in the control suffered seasonal fluctuations that were similar to the trends observed on the Ulva spp. side of the Ulva-Zostera ecotone, with the highest abundances detected in the summer (Fig. 3A; one-way ANOVA, $F_{6,42}=4.29, p=0.0019$ ).

Density of Zostera marina also changed spatially, but not seasonally (Fig. 3A; two-way ANOVA, Distance: $F_{6,238}=152.28, p<0.0001$, Season: $F_{6,238}=1.38$, $p=0.2235$, Distance $x$ Season: $F_{36,238}=0.56, p=0.9782$ ). The highest density of 
Zostera marina was observed $15 \mathrm{~m}$ away from the ecotone boundary and into the Zostera bed, and density values decreased with proximity to the boundary. Mean Zostera marina density values remained constant throughout the year, and spatial patterns across the ecotone were consistent through time.

Overall, there was a negative correlation between density of Ulva spp. and density of Zostera marina across the ecotone (Fig. 3B; Nonlinear Regression, $\left.F_{1,243}=89.99, p<0.0001, R^{2}=0.61\right)$, and both were found at similar densities at the boundary. 

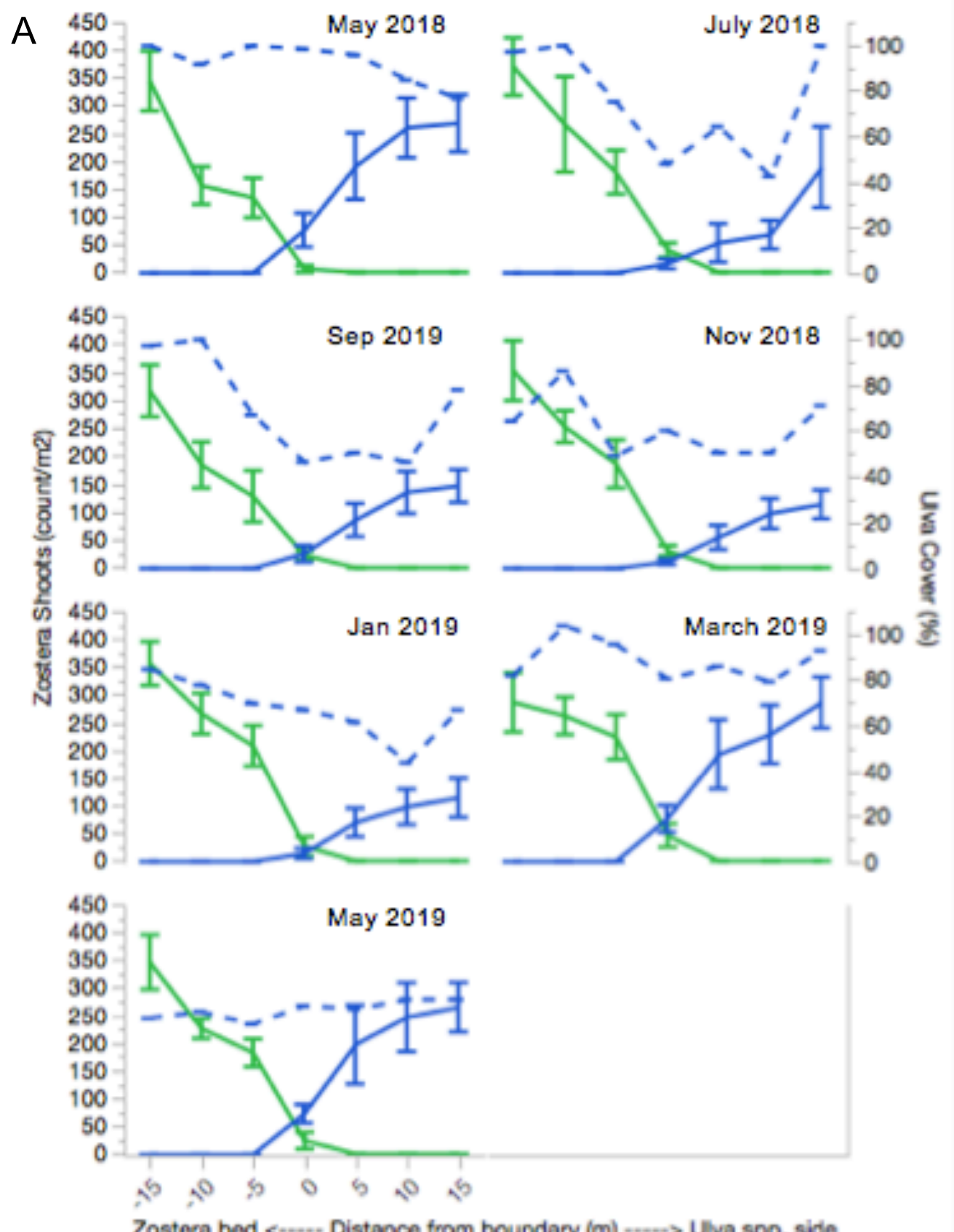

Zostera bed $<\cdots-$ Distance from boundary $(m) ~ m-\cdots$ Ulva spp. side

- Zostera marina - Ulva spp. - - Ulva spp. control 


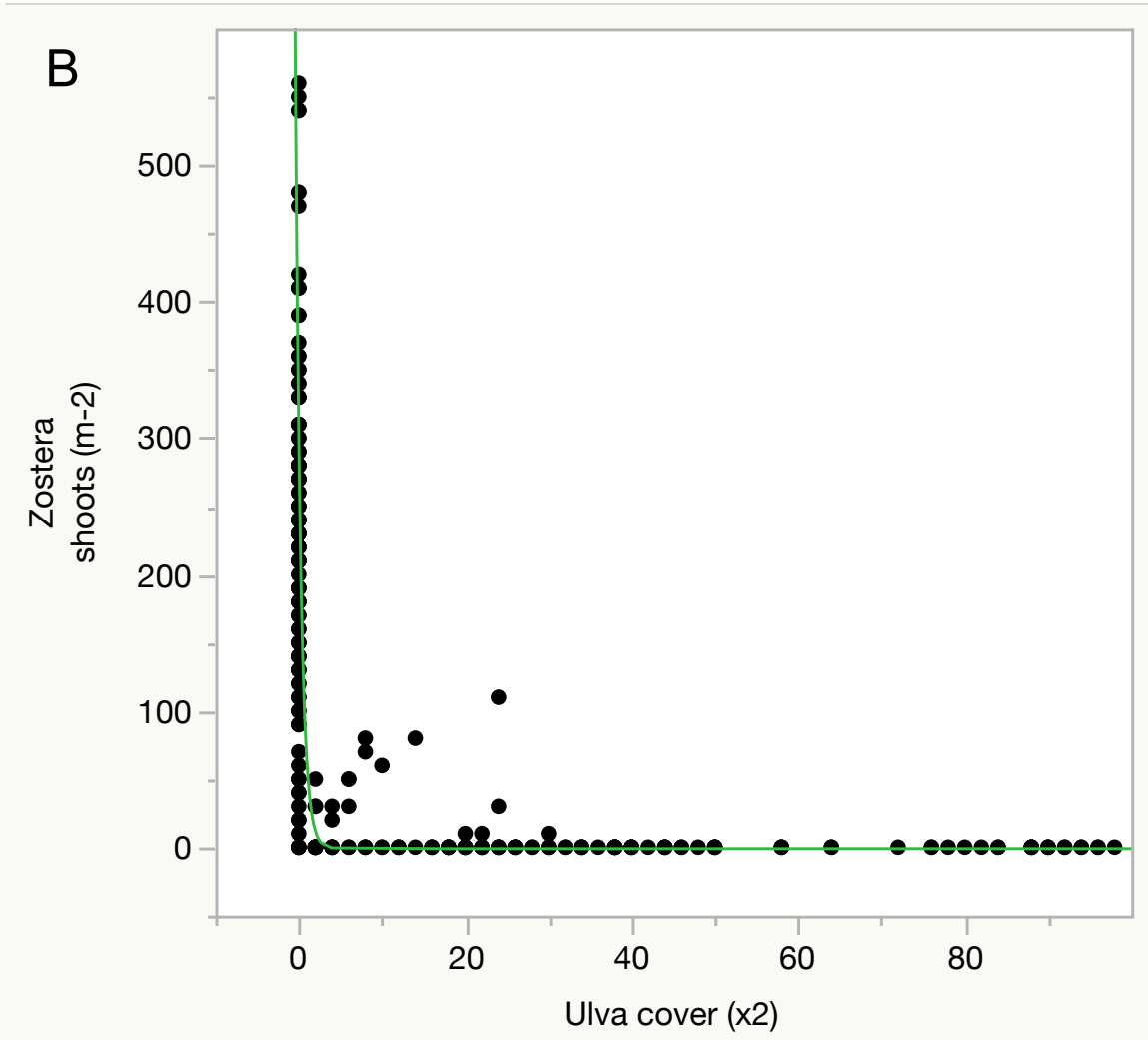

Figure 3. Macrophyte abundance across the ecotone. (A) Seasonal macrophyte abundance fluctuations across the ecotone. Green lines represent mean density of Zostera marina in shoots $/ \mathrm{m}^{2}$ across the ecotone $(\mathrm{N}=245)$. Continuous blue lines represent mean Ulva spp. cover in percentage across the ecotone $(\mathrm{N}=245)$. Discontinuous blue lines represent mean Ulva spp. cover in percentage across the control $(\mathrm{N}=49)$. Error bars represent standard error of the mean due to variability between transects. (B) Relationship between Ulva spp. abundance and Zostera marina abundance. There is a nonlinear correlation between Zostera marina abundance and Ulva spp. abundance. The green curve represents the best-fit model $\left(R^{2}=0.61\right)$.

\section{Boundary Shift}

The relative abundance of macrophytes did not vary sigificantly across seasons at the boundary of the Ulva-Zostera ecotone. Proximity of Ulva spp. to the ecotone boundary was slightly greater in the summer and fall than in the winter and spring months but did not vary significantly with time (Fig. 4; Kruskal- 
Wallis, $\mathrm{df}=6, \mathrm{X}^{2}=6.86, \mathrm{p}=0.3340$ ). Proximity of Zostera marina to the mark initially designated as the ecotone boundary did not change throughout the duration of the study (Fig. 4; Kruskal-Wallis, $d f=6, X^{2}=0.36, p=0.9992$ ). Subsequently, both the width of the transitional area and the placement of the boundary relative to tidal height remained constant throughout the year (Fig. 4; Kruskal-Wallis, df=6, $\left.X^{2}=3.65, p=0.7237\right)$. These trends were consistent with macrophyte density observations at other marks across the ecotone.

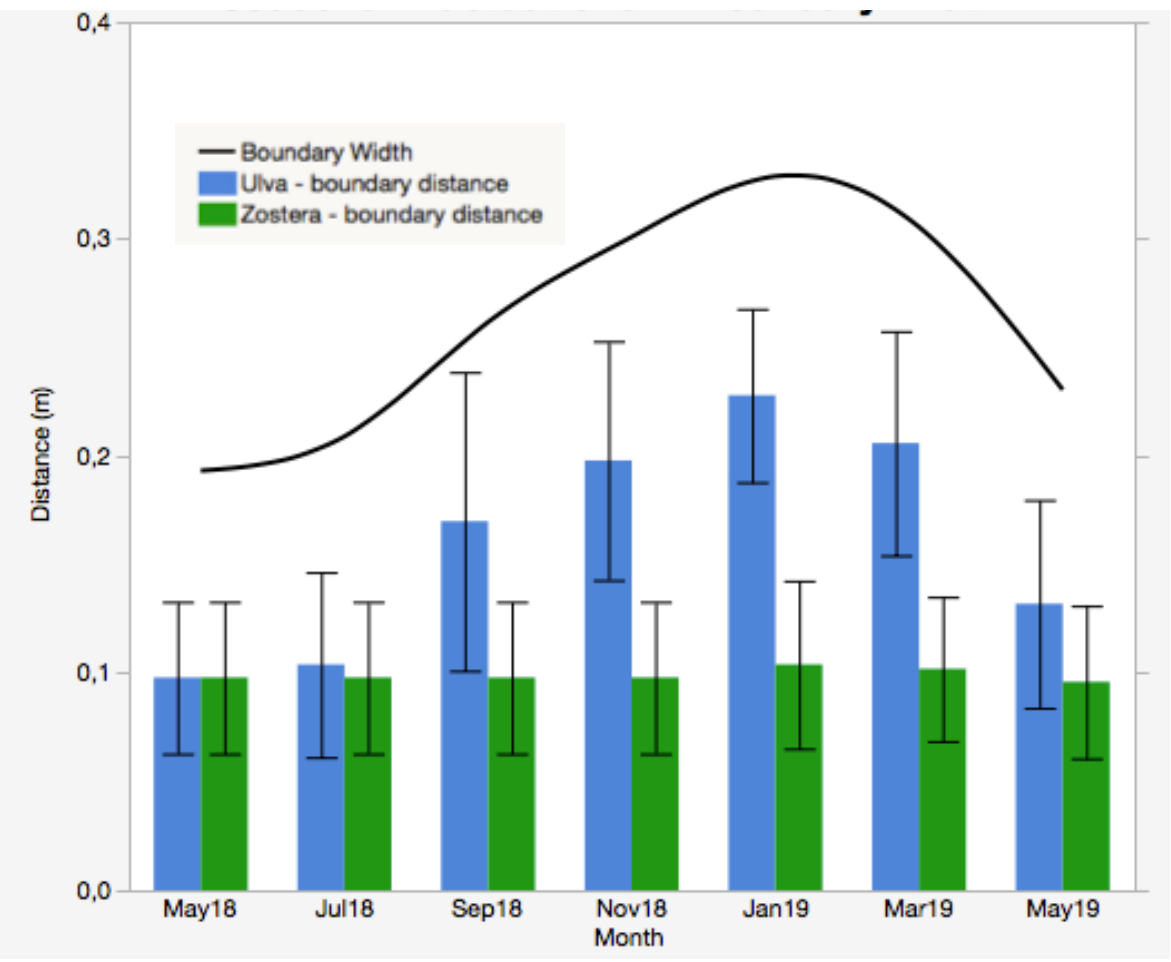

Figure 4. Seasonal changes in width of the ecotone boundary. Blue bars represent the distance between the ecotone boundary and the closest Ulva spp. patch in meters $(\mathrm{N}=35)$. Green bars represent the distance between the ecotone boundary and the edge of the Zostera marina bed in meters $(\mathrm{N}=35)$. Error bars represent standard error of the mean due to variability between transects. The black line represents the boundary width in meters $(\mathrm{N}=35)$. 


\section{Water Quality}

Water quality varied significantly across the ecotone and throughout the year. Water temperature consistently decreased with increasing distance from the boundary through all sampling periods (Fig. 5; two-way ANOVA, Distance:

$F_{3,112}=19.78, p<0.0001$, Season: $F_{6,112}=274.05, p<0.0001$, Distance $x$ Season: $\left.F_{18,112}=0.29, p=0.9981\right)$. Average water temperature across the ecotone changed significantly throughout the year, with higher temperatures in the summer months. 


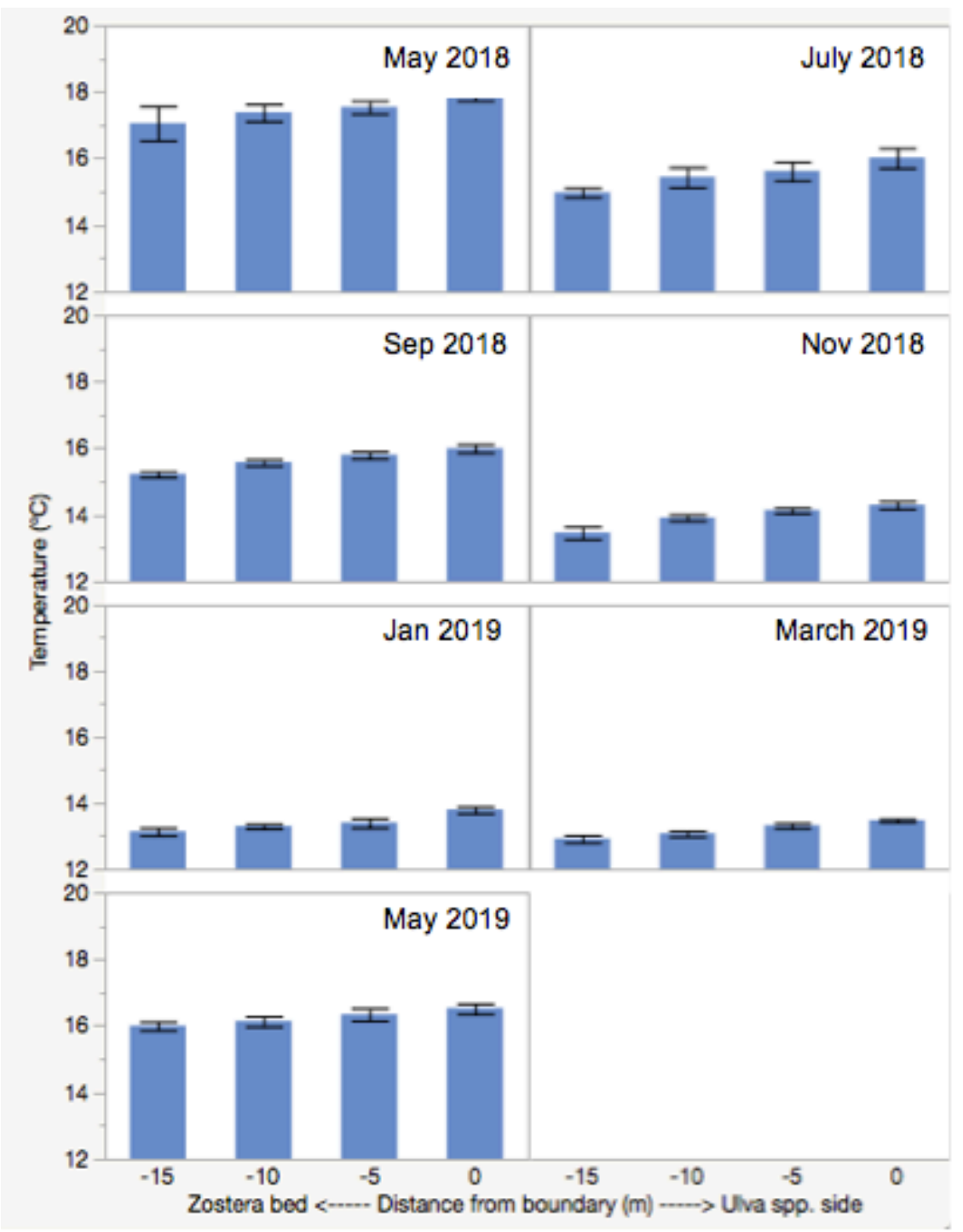

Figure 5. Seasonal temperature fluctuations across the ecotone. Blue bars represent mean temperature values at the ecotone boundary and at distances of $5-15 m$ away from the boundary throughout the year $(\mathrm{N}=140)$ in Celsius. Error bars represent standard error of the mean due to variability between transects.

Salinity suffered significant seasonal changes, but no spatial changes across the ecotone (Fig. 6; two-way ANOVA, Distance: $F_{3,112}=2.14, p=0.0993$, Season: $F_{6,112}=119.21, p<0.0001$, Distance $\times$ Season: $\left.F_{18,112}=0.45, p=0.9732\right)$. Lower salinity values were detected in the winter months, but there were consistently no 
significant spatial differences in salinity across the ecotone at any sampling period.

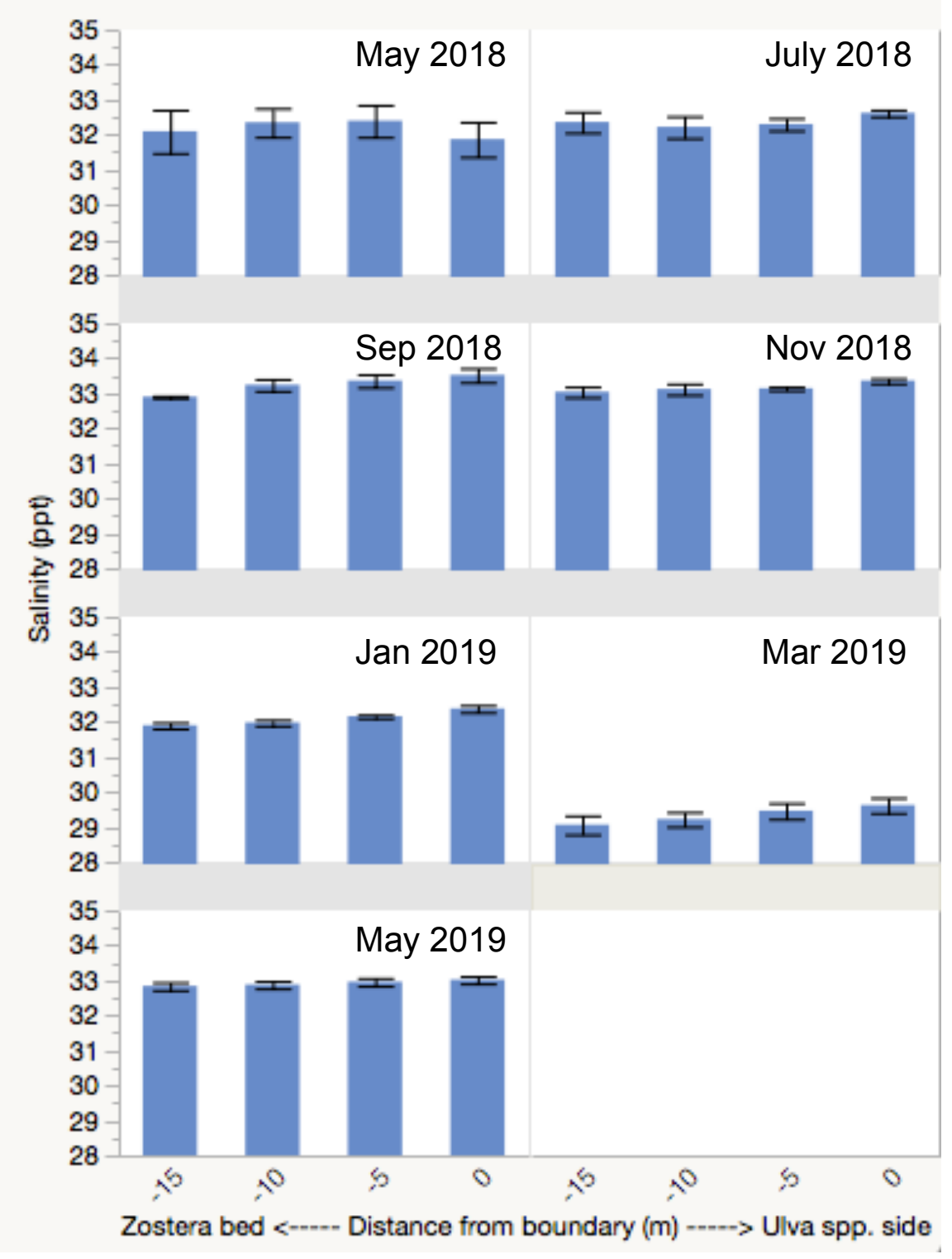

Figure 6. Seasonal salinity fluctuations across the ecotone. Blue bars represent mean salinity values at the ecotone boundary and at distances of 5$15 \mathrm{~m}$ away from the boundary throughout the year $(\mathrm{N}=140)$ in parts per thousand. Error bars represent standard error of the mean due to variability between transects. 
Similarly, pH levels did not change significantly across the ecotone, but did change throughout the year (Fig. 7; two-way ANOVA, Distance: $F_{3,112}=0.75$, $p=0.5216$, Season: $F_{6,112}=20.89, p<0.0001$, Distance $x$ Season: $F_{18,112}=0.49$, $\mathrm{p}=0.9558)$. Higher $\mathrm{pH}$ values were detected in the summer months than other seasons. However, pH values were not significantly different at different distances from the boundaty, a trend that was consistent through time. 


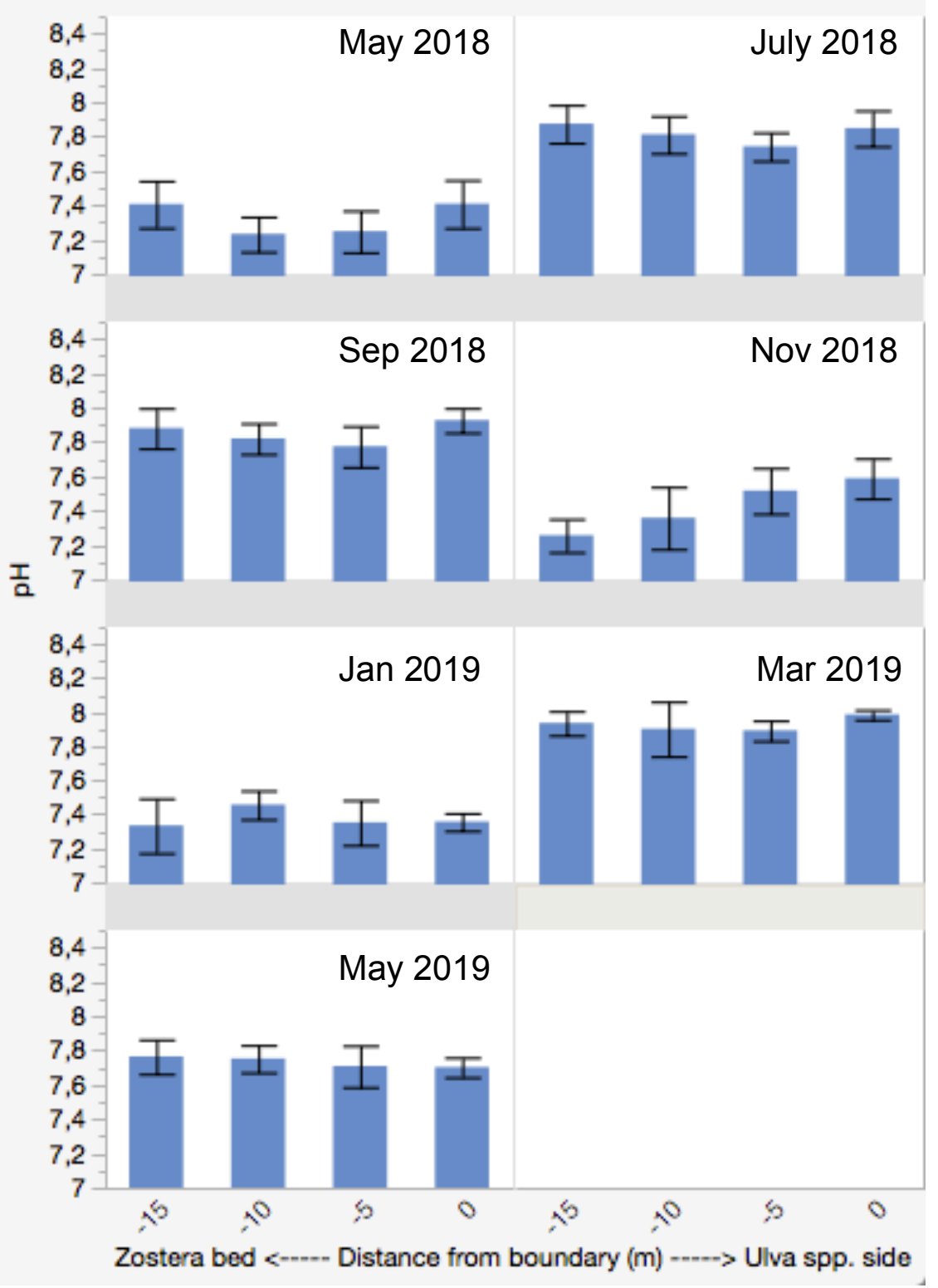

Figure 7. Seasonal pH fluctuations across the ecotone. Blue bars represent mean $\mathrm{pH}$ values at the ecotone boundary and at distances of 5-15m away from the boundary throughout the year $(\mathrm{N}=140)$. Error bars represent standard error of the mean due to variability between transects. 
On the other hand, dissolved oxygen values were significantly different across seasons and across the ecotone (Fig. 8; two-way ANOVA, Distance:

$F_{3,112}=18.42, p<0.0001$, Season: $F_{6,112}=F_{6,112}=26.70, p<0.0001$, Distance $x$ Season: $\left.F_{18,112}=0.41, p=0.9835\right)$. Dissolved oxygen concentrations were higher during the winter months, decreased with distance from the boundary, and spatial patterns were consistent over time. 


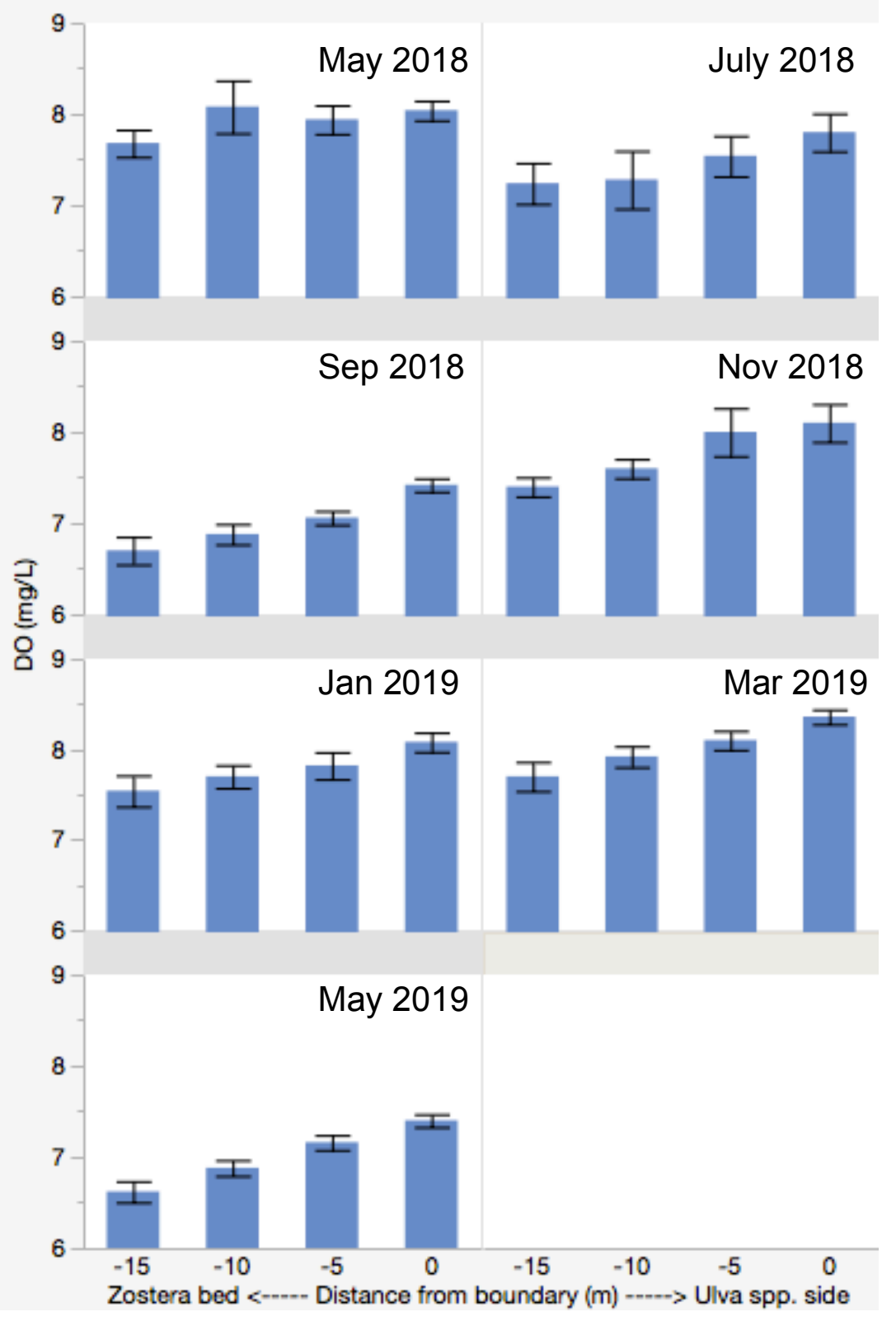

Figure 8. Seasonal dissolved oxygen fluctuations across the ecotone. Blue bars represent mean dissolved oxygen values at the ecotone boundary and at distances of $5-15 \mathrm{~m}$ away from the boundary throughout the year $(\mathrm{N}=140)$ in milligrams per liter. Error bars represent standard error of the mean due to variability between transects. 


\section{Sediment Characteristics}

Porewater Nutrients: Phosphate levels were significantly different across the ecotone and throughout the year (Fig. 9; two-way ANOVA, Distance: $F_{2,81}=5.02$, $p=0.0088$, Season: $F_{6,81}=4.01, p=0.0015$, Distance $\times$ Season: $F_{12,81}=3.58$, $\mathrm{p}=0.0003$ ). Phosphate concentrations ranged from $0-15 \mu \mathrm{M}$ in both the Zostera bed and the ecotone boundary, and reached concentrations of up to $52 \mu \mathrm{M}$ on the Ulva spp. side. There were also significant seasonal changes, with higher phosphate concentrations in the spring, and lower concentrations in the fall and winter. However, patterns in phosphate concentration along transects were not consistent across seasons, since the increase in concentration on the Ulva spp. side of the ecotone was much stronger in the spring and summer of 2018 than other seasons. 


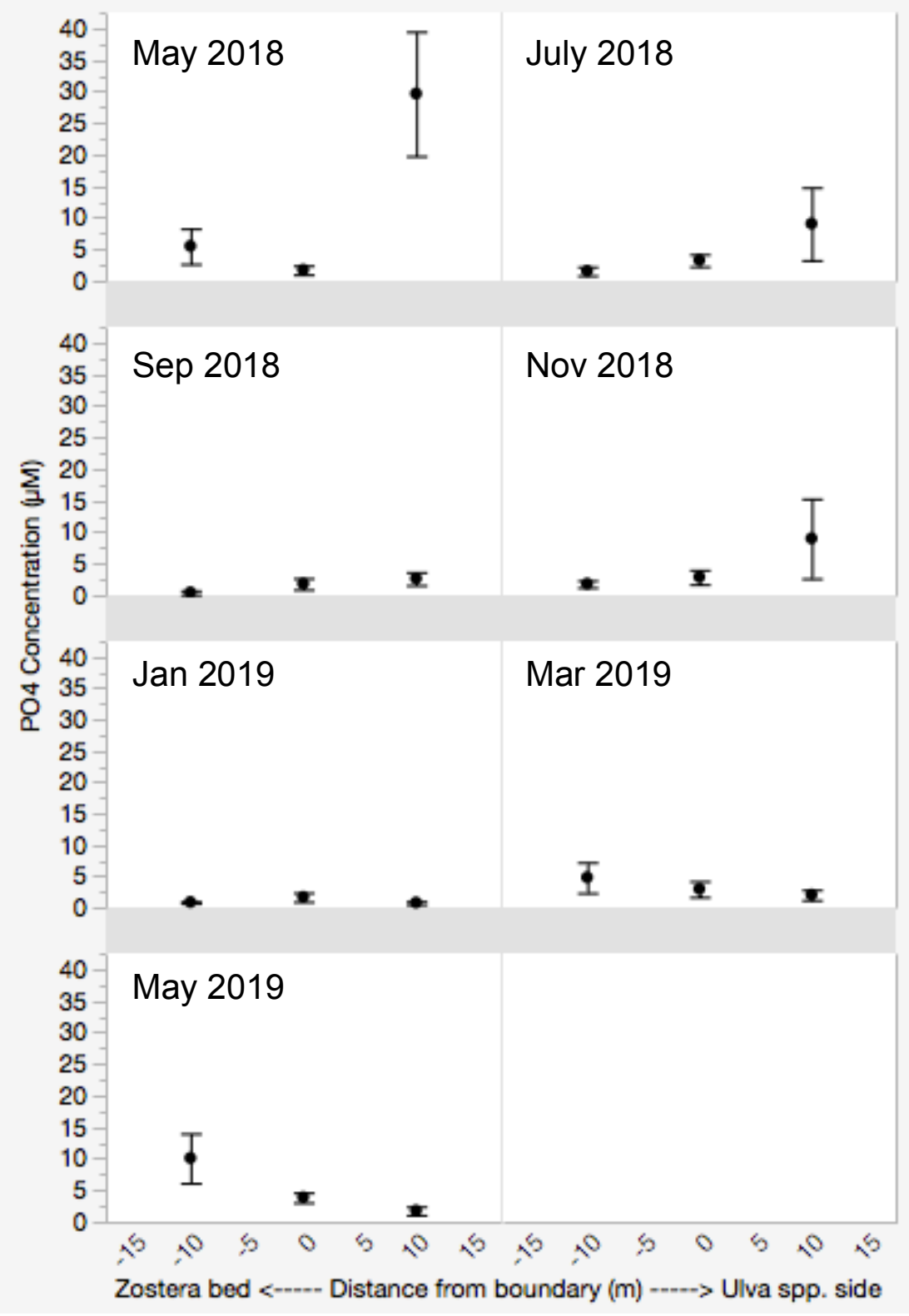

Figure 9. Porewater phosphate concentrations across the ecotone. Black points represent mean phosphate concentration values at the ecotone boundary and a distance of $10 \mathrm{~m}$ away from the boundary on either side throughout the year $(\mathrm{N}=102)$ in micromolar. Error bars represent standard error of the mean due to variability between transects. 
Nitrate concentrations were not significantly different across the ecotone, but did differ across seasons (Fig. 10; two-way ANOVA, Distance: $F_{2,81}=0.53$, $p=0.5878$, Season: $F_{6,81}=16.23, p<0.0001$, Distance $x$ Season: $F_{12,81}=0.63$, $\mathrm{p}=0.8071)$. Nitrate concentrations ranged from $0-5 \mu \mathrm{M}$ in the Zostera bed, the ecotone boundary, and the Ulva spp. side, a consistent pattern across seasons. However, greater concentrations of porewater nitrate were measured in the summer, and lower concentrations in the fall and winter. 


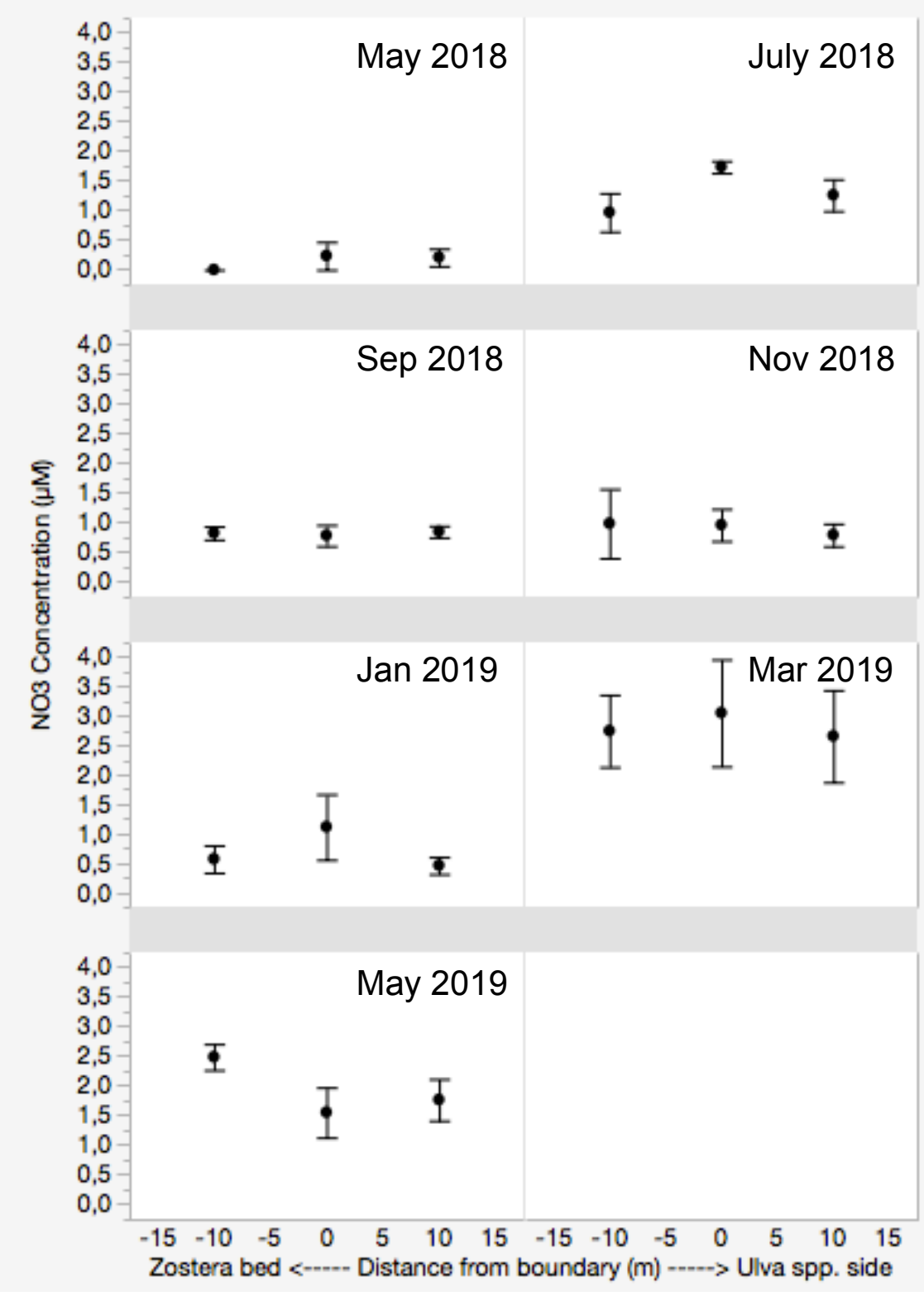

Figure 10. Porewater nitrate concentrations across the ecotone. Black points represent mean nitrate concentration values at the ecotone boundary and a distance of $10 \mathrm{~m}$ away from the boundary on either side throughout the year $(\mathrm{N}=102)$ in micromolar. Error bars represent standard error of the mean due to variability between transects. 
Porewater ammonium levels differed significantly across the ecotone, although there were no significant seasonal differences detected (Fig. 11; twoway ANOVA, Distance: $F_{2,81}=24.78, p<0.0001$, Season: $F_{6,81}=1.88, p=0.0941$, Distance $x$ Season: $\left.F_{12,81}=1.56, p=0.1216\right)$. Ammonium concentrations ranged from $50-490 \mu \mathrm{M}$ in the Zostera bed, and from $0-150 \mu \mathrm{M}$ in both the ecotone boundary and the Ulva spp. side. Although seasonal differences were not significant, there were slightly lower average ammonium concentrations across the entire ecotone in September 2018. The spatial patterns detected in ammonium concentrations were consistent through time. 


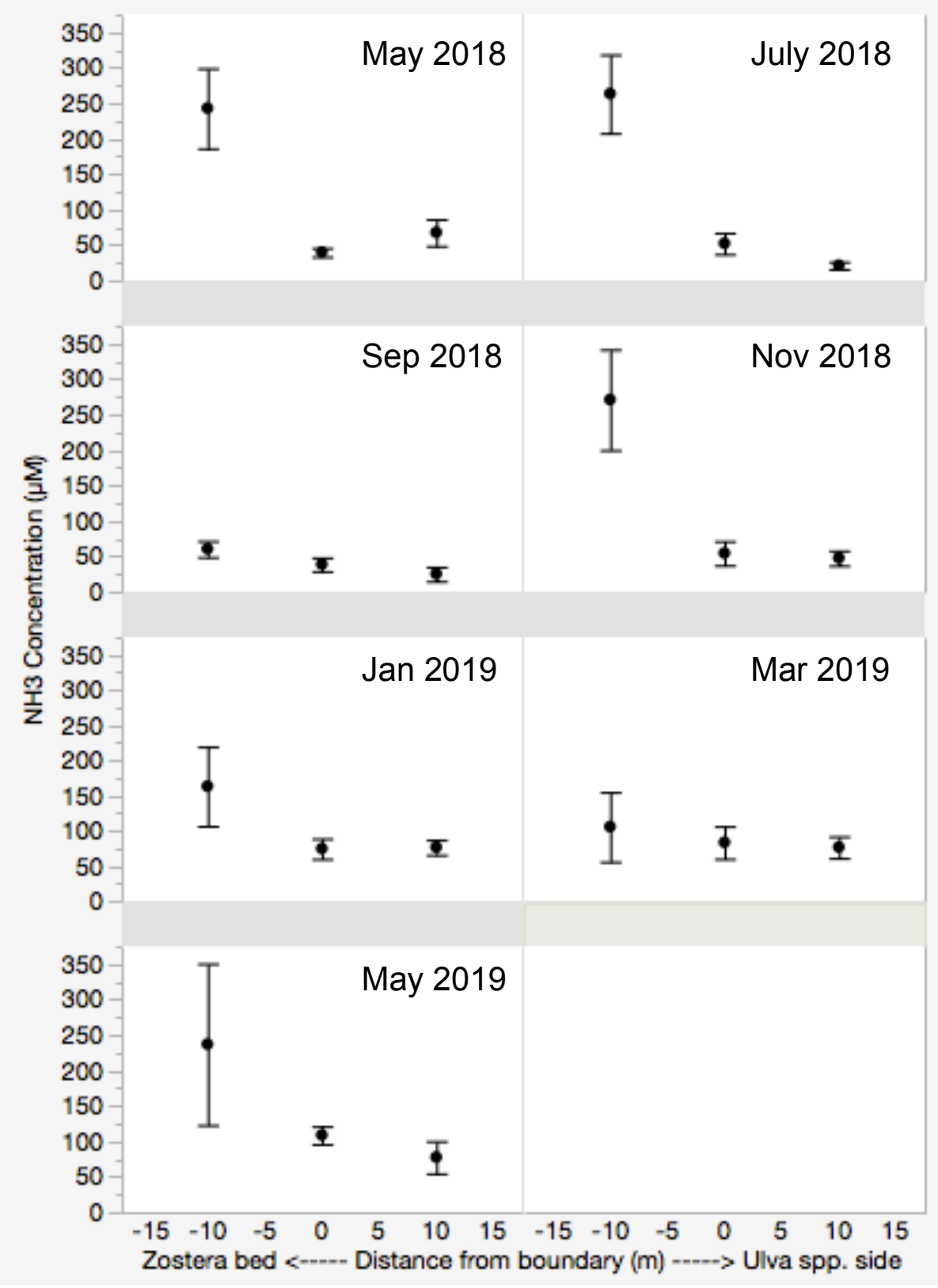

Figure 11. Porewater ammonium concentrations across the ecotone. Black points represent mean ammonium concentration values at the ecotone boundary and a distance of $10 \mathrm{~m}$ away from the boundary on either side throughout the year $(\mathrm{N}=102)$ in micromolar. Error bars represent standard error of the mean due to variability between transects. 
Grain-Size Analysis: At Seal Bend, the sediment was mostly composed of fine-medium silt and clay. As expected, grain size differed significantly across the ecotone and across seasons (Fig. 12A; two-way ANOVA, Distance: $F_{2,84}=22.28$, $p<0.0001$, Season: $F_{6,84}=3.02, p=0.0101$, Distance $x$ Season: $F_{12,84}=0.94$, $p=0.5106)$. Mean grain size was not different between the ecotone boundary and the Ulva spp. side, ranging from 3.5-8 $\mu \mathrm{m}$ at both marks. Mean grain size was higher in the eelgrass bed, ranging from 3.8-11 $\mu \mathrm{m}$. While the sediment was composed of clay and fine silt at the ecotone boundary and the Ulva spp. side, there was a large proportion of medium silt in the eelgrass bed consistently across sampling periods. There were also significant seasonal differences detected, with slightly higher grain sizes in the spring and summer than in the fall. Grain-size distribution across the ecotone did was not linked to hydraulic conditions (Fig. 12B).

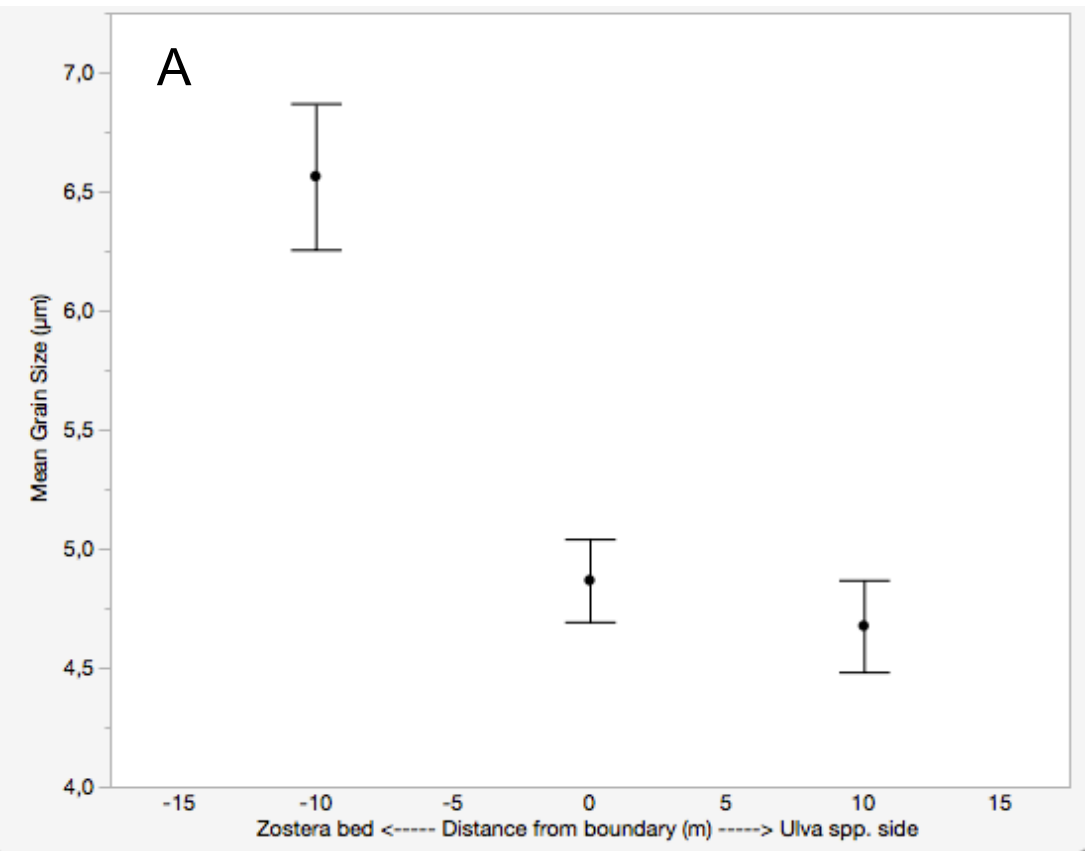




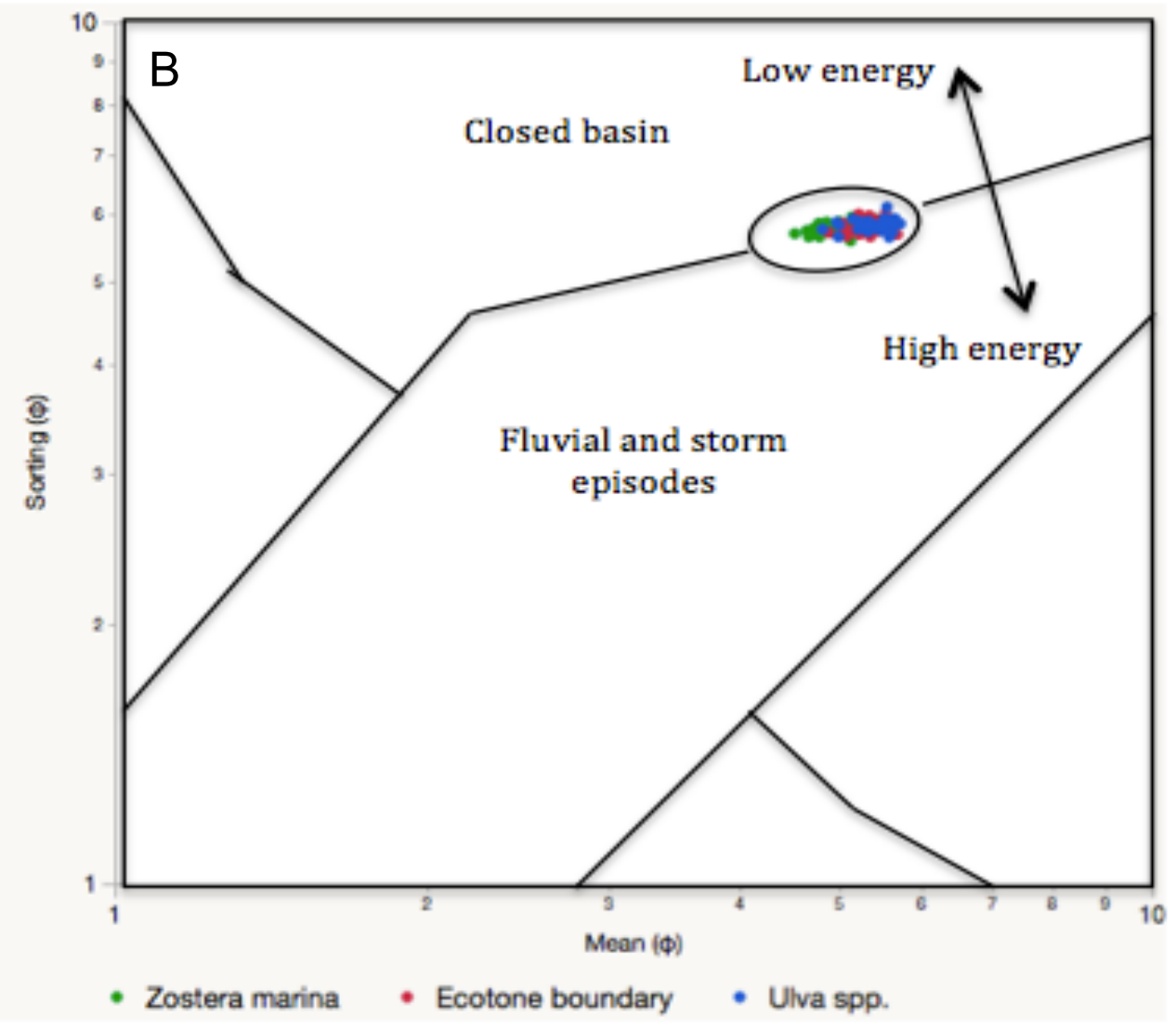

Figure 12. Sediment composition across the ecotone.

(A) Grain size distribution across the ecotone. Black points represent mean grain size values at the ecotone boundary and a distance of $10 \mathrm{~m}$ away from the boundary on either side throughout the year $(\mathrm{N}=105)$ in micrometers. Error bars represent standard error of the mean due to variability between transects. (B) Bivariate plot of mean grain size against sorting. Points within the elipse represent mean grain size values against standard deviation at the ecotone boundary and a distance of $10 \mathrm{~m}$ away from the boundary on either side $(\mathrm{N}=105)$. Green points were calculated from cores taken in the Zostera marina bed, red points from the ecotone boundary, and blue points from the Ulva spp. side. Measurements in micrometers were converted into the equivalent phi $(\varphi)$ values and are plotted in a $\varphi$-scale. The bivariate plot incorporates the domains defined by Tanner (1991) and Lario (2002) to determine if grain-size distribution across the ecotone might be linked to hydraulic conditions. There is likely another explanation for the particle size distribution, since the majority of the larger particles (green points) fall in the low depositional energy section of the plot, which invalidates the hydraulic sorting theory. 
Although there were no significant spatial differences in particle heterogeneity across the ecotone, there were significant seasonal differences (Fig. 13; two-way ANOVA, Distance: $F_{2,84}=1.30, p=0.2777$, Season: $F_{6,84}=2.92, p=0.0123$, Distance $x$ Season: $\left.F_{12,84}=1.19, p=0.3035\right)$. Sediment composition was more heterogeneous in the fall and winter, and spatial patterns detected were consistent through the duration of the study. 


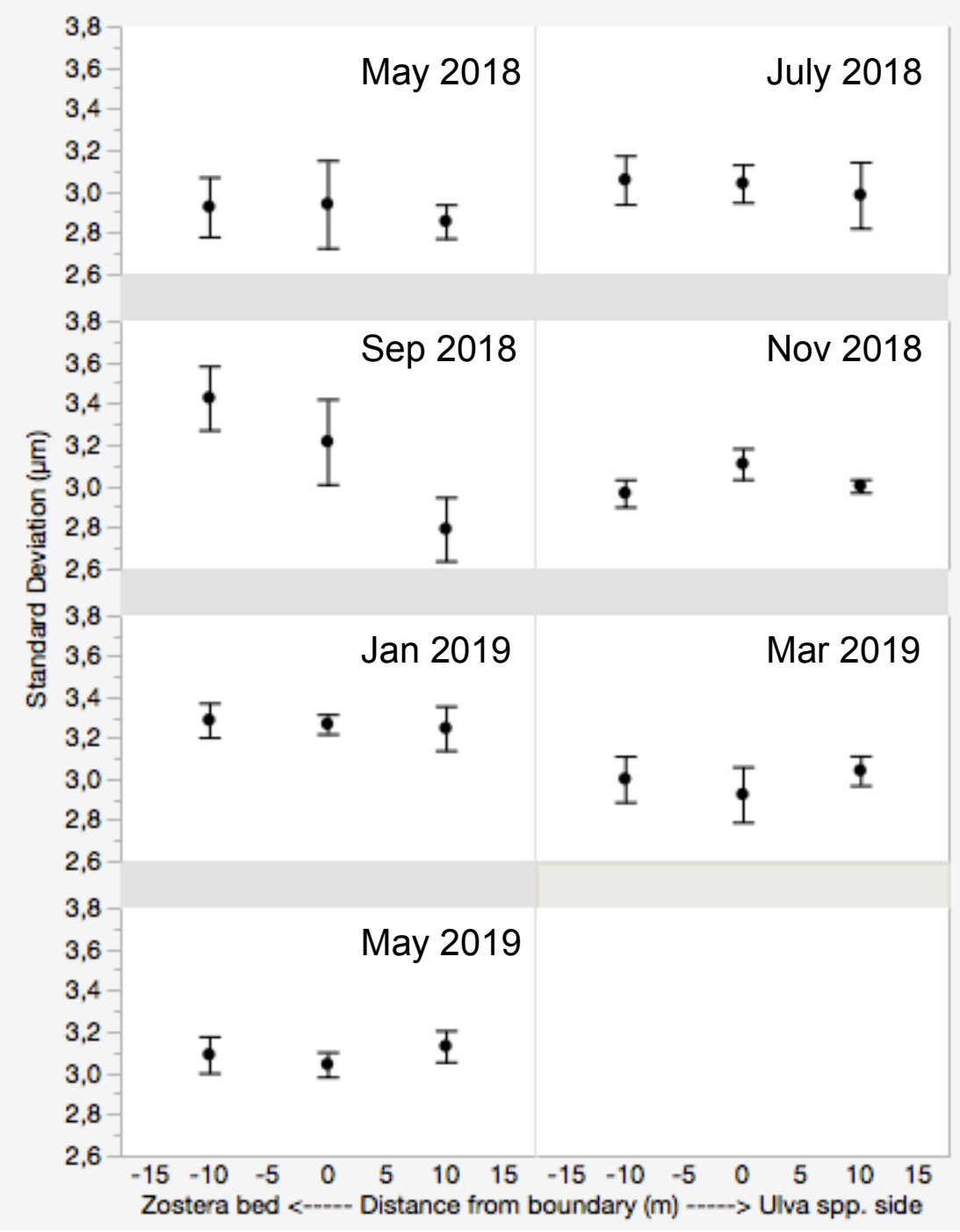

Figure 13. Particle heterogeneity across the ecotone throughout the year. Black points represent mean particle heterogeneity values as a function of standard deviation of grain size at the ecotone boundary and a distance of $10 \mathrm{~m}$ away from the boundary on either side throughout the year $(\mathrm{N}=105)$ in micrometers. Error bars represent standard error of the mean due to variability between transects. 


\section{Recruitment Observations}

Presence of Ulva spp. (Y/N) on the nylon ropes attached to PVC pipes varied significantly across the ecotone, but it did not change throughout the year (Fig. 14; GLM, Distance: $X^{2} 6,196=256.55, p<0.0001$, Season: $X^{2} 6,196=0.02, p=1.0000$, Distance $x$ Season: $\left.X^{2}{ }_{36,196}=17.27, p=0.9965\right)$. Recruitment success was greatest $10-15 \mathrm{~m}$ into the Ulva spp. zone, which was also where the greatest cover of Ulva spp. was calculated in the macrophyte density estimates. Recruitment success was approximately $20 \%$ on average at the boundary and there was no recruitment inside the eelgrass bed. There were no significant differences in recruitment success at the different distances from the boundary within each side of the boundary. On the other hand, recruitment success did not significantly vary spatially or seasonally in the control transect (Fig. 14; GLM, Distance:

$X^{2} 6,42=0.002, p=1.000$, Season: $X^{2} 6,42=0.004, p=1.0000$, Distance $x$ Season: $\left.X^{2} 36,42=0.007, p=1.0000\right)$. Recruitment success was extremely high at all marks on the control transect. Spatial trends in recruitment success remained constant throughout the year at the Ulva-Zostera ecotone and the control. 


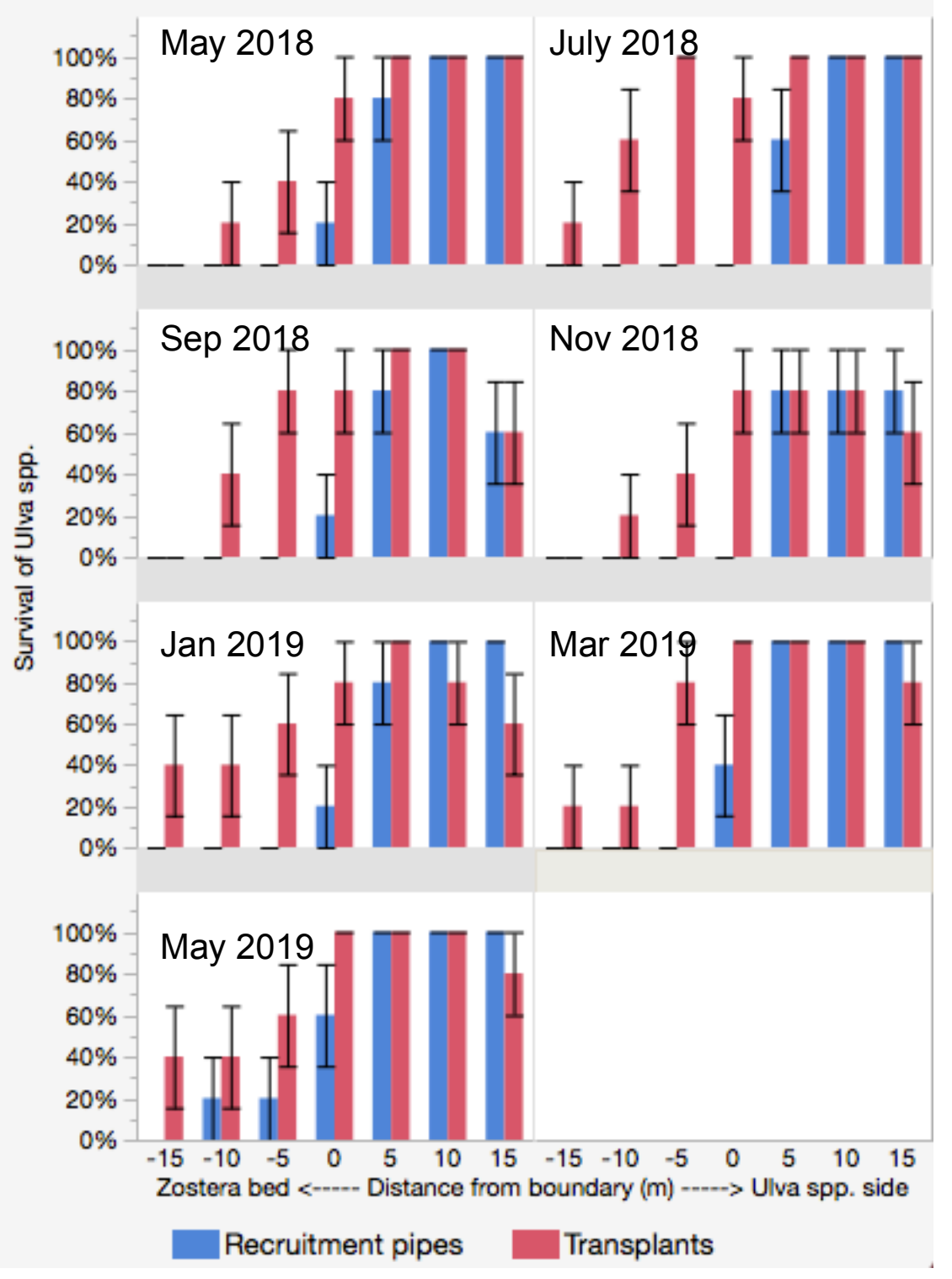

Figure 14. Recruitment and transplant success across the ecotone throughout the year. Blue bars represent mean recruitment success (binary response) across the ecotone as a percentage $(\mathrm{N}=245)$. Red bars represent mean transplant success (binary response) across the ecotone as a percentage $(\mathrm{N}=245)$. Error bars represent standard error of the mean due to variability between transects. 
Percent cover of Ulva spp. on the surface of the rope varied significantly across the ecotone and across seasons (Fig. 15; two-way ANOVA, Distance: $F_{6,196}=79.35, p<0.0001$, Season: $F_{6,196}=7.14, p<0.0001$, Distance $x$ Season: $\left.F_{36,196}=2.19, p=0.0004\right)$. Despite spatial differences along transects, percent cover values were similar between all distances from the boundary within each side of the ecotone. There was significantly greater percent cover of Ulva spp. on recruitment pipes in the spring and summer months. Spatial trends in Ulva spp. cover were not consistent across seasons, with stronger increase in percent cover on the Ulva spp. side of the ecotone in the spring and summer than other seasons. Macroalgal cover differed significantly among seasons in the control (one-way ANOVA, $F_{6,40}=3.02, p=0.0137$ ), with less cover during the fall and winter. Unlike what was seen across the Ulva-Zostera ecotone, Ulva spp. cover on recruitment pipes remained constant across the control (one-way ANOVA, $\left.F_{6,40}=0.54, p=0.7746\right)$. 


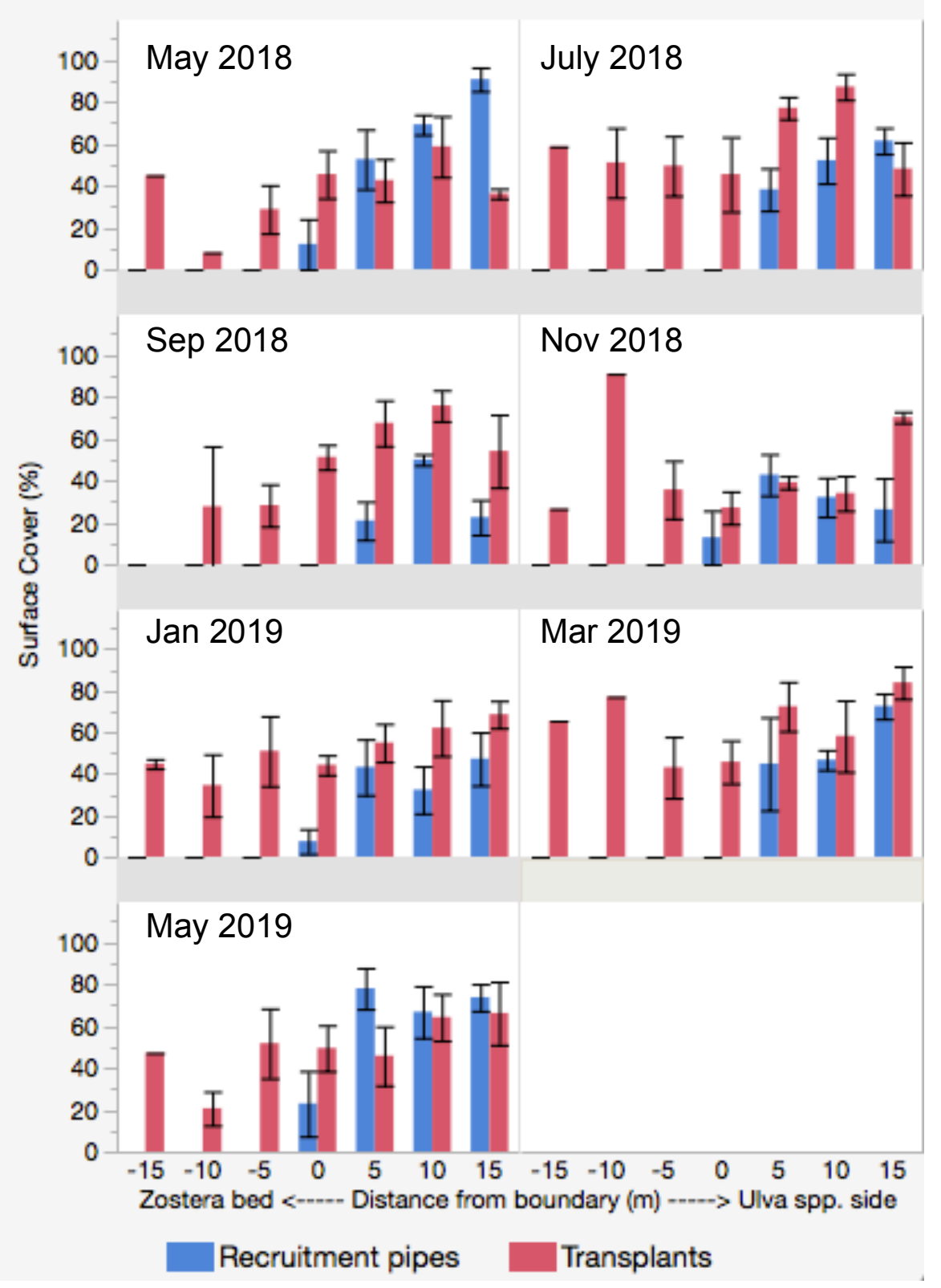

Figure 15. Percent cover of Ulva spp. on recruitment and transplant pipes. Blue bars represent mean percent cover of Ulva spp. on recruitment pipes across the ecotone $(\mathrm{N}=245)$. Red bars represent mean percent cover of Ulva spp. on transplants across the ecotone $(\mathrm{N}=245)$. Error bars represent standard error of the mean due to variability between transects. 
New Ulva spp. biomass on the recruitment pipes varied significantly across the ecotone and throughout the duration of the study (Fig. 16; two-way ANOVA, Distance: $F_{6,196}=30.37, p<0.0001$, Season: $F_{6,196}=6.12, p<0.0001$, Distance $x$ Season: $\left.F_{36,196}=1.53, p=0.0370\right)$. The highest biomass values were recorded 15 $m$ into the Ulva spp. zone, and in the spring and fall months. However, these spatial trends were not consistent throughout the year, with stronger increase in biomass with increasing distance from the ecotone boundary in the fall and winter than in the spring and summer months. Biomass of Ulva spp. that recruited to the lines of rope placed in the control showed similar trends to Ulva spp. percent cover on the control, with only significant seasonal (Fig. 16; KruskalWallis, $d f=6, x^{2}=33.87, p<0.0001$ ) but no spatial (Fig. 16; Kruskal-Wallis, $d f=6$, $\left.X^{2}=4.01, p=0.6759\right)$ variability . 


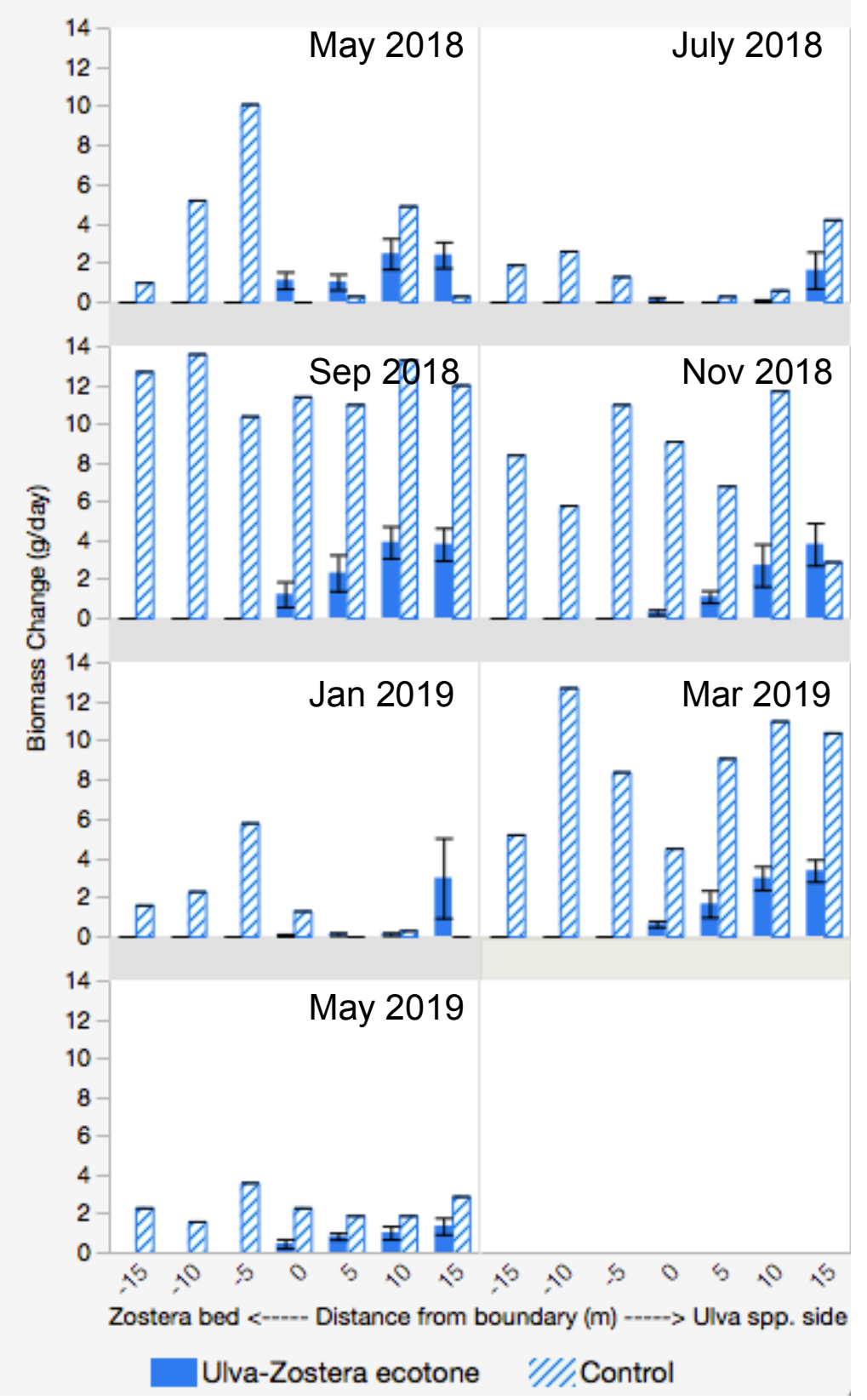

Figure 16. Change in Ulva spp. biomass on recruitment pipes across the ecotone. Filled bars represent daily change in Ulva spp. biomass across the Ulva-Zostera ecotone $(\mathrm{N}=245)$. Error bars represent standard error of the mean due to variability between transects. Bars with diagonal lines represent daily change in Ulva spp. biomass across the control $(\mathrm{N}=49)$. 


\section{Transplant Experiments}

Survival rate of transplanted Ulva spp. $(\mathrm{Y} / \mathrm{N})$ varied with distance from the ecotone boundary and across seasons (Fig. 14; GLM, Distance: $X^{2} 6,196=112.7$, $p<0.0001$, Season: $X^{2}{ }_{6,196}=15.99, p=0.0138$, Distance $x$ Season: $X^{2}{ }_{36,196}=27.29$, $p=0.8515)$. On the Ulva spp. side, transplant success was higher than in the Zostera bed, but success rates were very similar within either side of the boundary. There were significant differences in survival of transplanted Ulva spp. throughout the year, with higher survival in the spring and summer than fall and winter months. Spatial trends in transplant survival remained constant throughout the year. In successful transplants, change in macroalgal percent cover after two weeks was significantly different across the ecotone and across seasons (Fig. 15; two-way ANOVA, Distance: $F_{6,117}=3.97, p=0.0023$, Season: $F_{6,117}=2.40$, $p=0.0413$, Distance $x$ Season: $\left.F_{36,117}=1.08, p=0.3649\right)$. There was less cover on transplanted pipes in the eelgrass bed than at the boundary or on the Ulva spp. side. Additionally, there was slightly higher percent cover of Ulva spp. during the summer, and spatial patterns were consistent throughout the duration of the study. Distance from the top of the ropes to the portion at which Ulva spp. was no longer present remained fairly constant across the ecotone and throughout the year (Fig. 17; two-way ANOVA, Distance: $F_{6,117}=1.39, p=0.2316$, Season: $F_{6,117}=0.36, p=0.7823$, Distance $x$ Season: $\left.F_{36,117}=1.39, p=0.2316\right)$. Spatial patterns observed in percent cover of Ulva spp. down the PVC pipes remained consistent across seasons. 


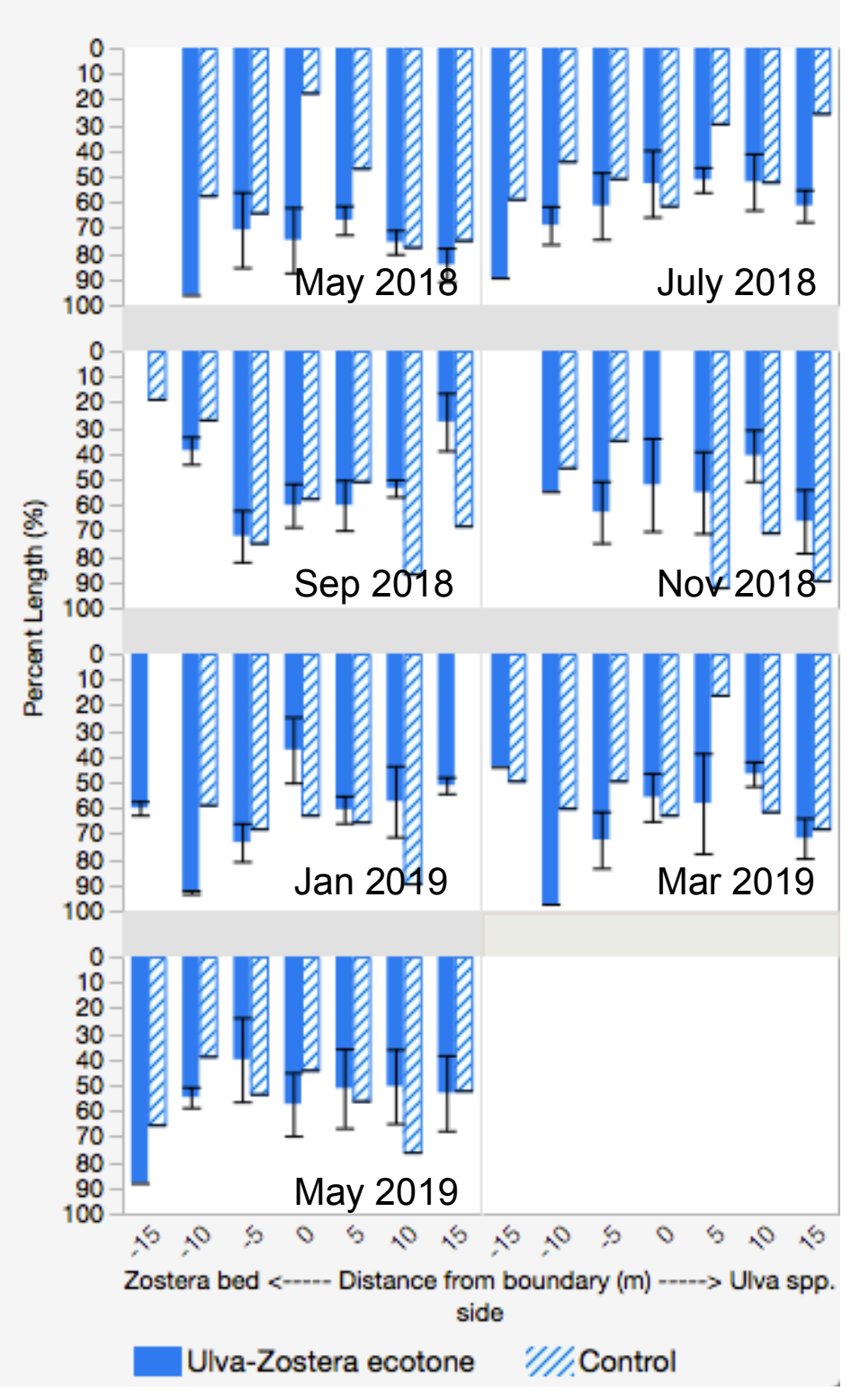

Figure 17. Percent length of rope covered by Ulva spp. on transplants.

Filled bars represent percent length of rope covered by Ulva spp. on transplants across the Ulva-Zostera ecotone $(\mathrm{N}=245)$. Error bars represent standard error of the mean due to variability between transects. Bars with diagonal lines represent percent length of rope covered by Ulva spp. on transplants across the control $(\mathrm{N}=49)$. 


\section{Grazing}

Biomass of small grazers differed significantly with distance to the ecotone boundary, but remained fairly constant throughout the year (Fig. 18; two-way ANOVA, Distance: $F_{6,196}=3.35, p=0.0036$, Season: $F_{6,196}=1.47, p=0.1916$, Distance $\times$ Season: $\left.F_{36,196}=0.79, p=0.7914\right)$. Higher biomass was measured at the ecotone boundary and $5 \mathrm{~m}$ into the eelgrass bed. Although mean small grazer biomass remained did not change significantly across seasons, slightly higher biomass was detected in the summer. 


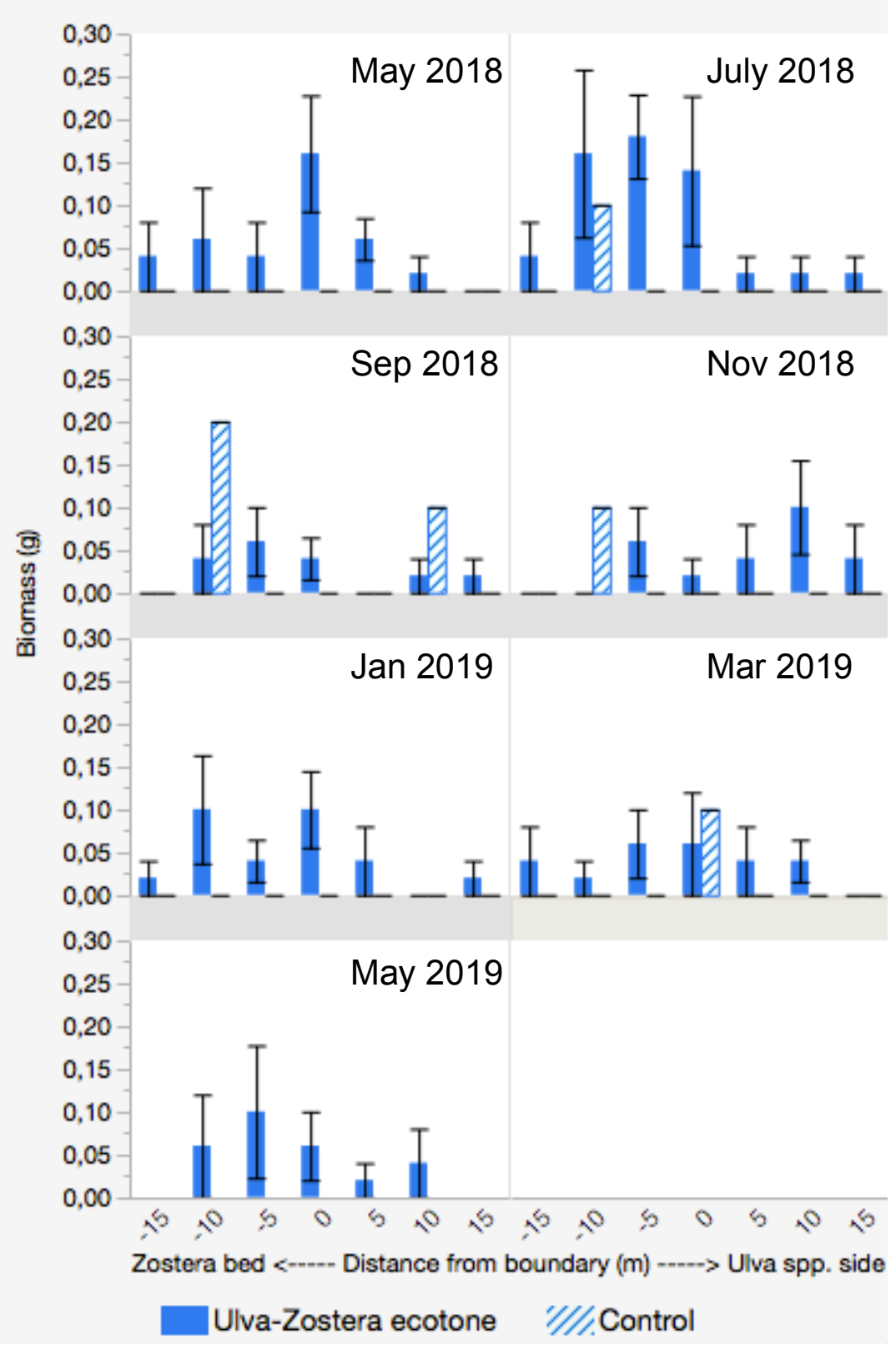

Figure 18. Biomass of small mesograzers across the ecotone. Filled bars represent small mesograzer biomass across the Ulva-Zostera ecotone $(\mathrm{N}=245)$. Error bars represent standard error of the mean due to variability between transects. Bars with diagonal lines represent small mesograzer biomass across the control $(\mathrm{N}=49)$. 
Density of large mesograzers differed significantly both with distance to the ecotone boundary and across seasons (Fig. 19; two-way ANOVA, Distance: $F_{6,196}=5.75, p<0.0001$, Season: $F_{6,196}=4.45, p=0.0003$, Distance $x$ Season: $\left.F_{36,196}=0.88, p=0.6679\right)$. Overall, grazer abundance was higher at the ecotone boundary, and 5-10 m into the eelgrass bed. Unlike small grazer biomass, density of large grazers changed significantly across sampling periods, with higher density in the spring and summer than in the fall and winter months. Spatial patterns in large grazer density remained consistent throughout the year. Grazer abundance followed a similar seasonal pattern in the control, but was only subject to small spatial changes across transects. 


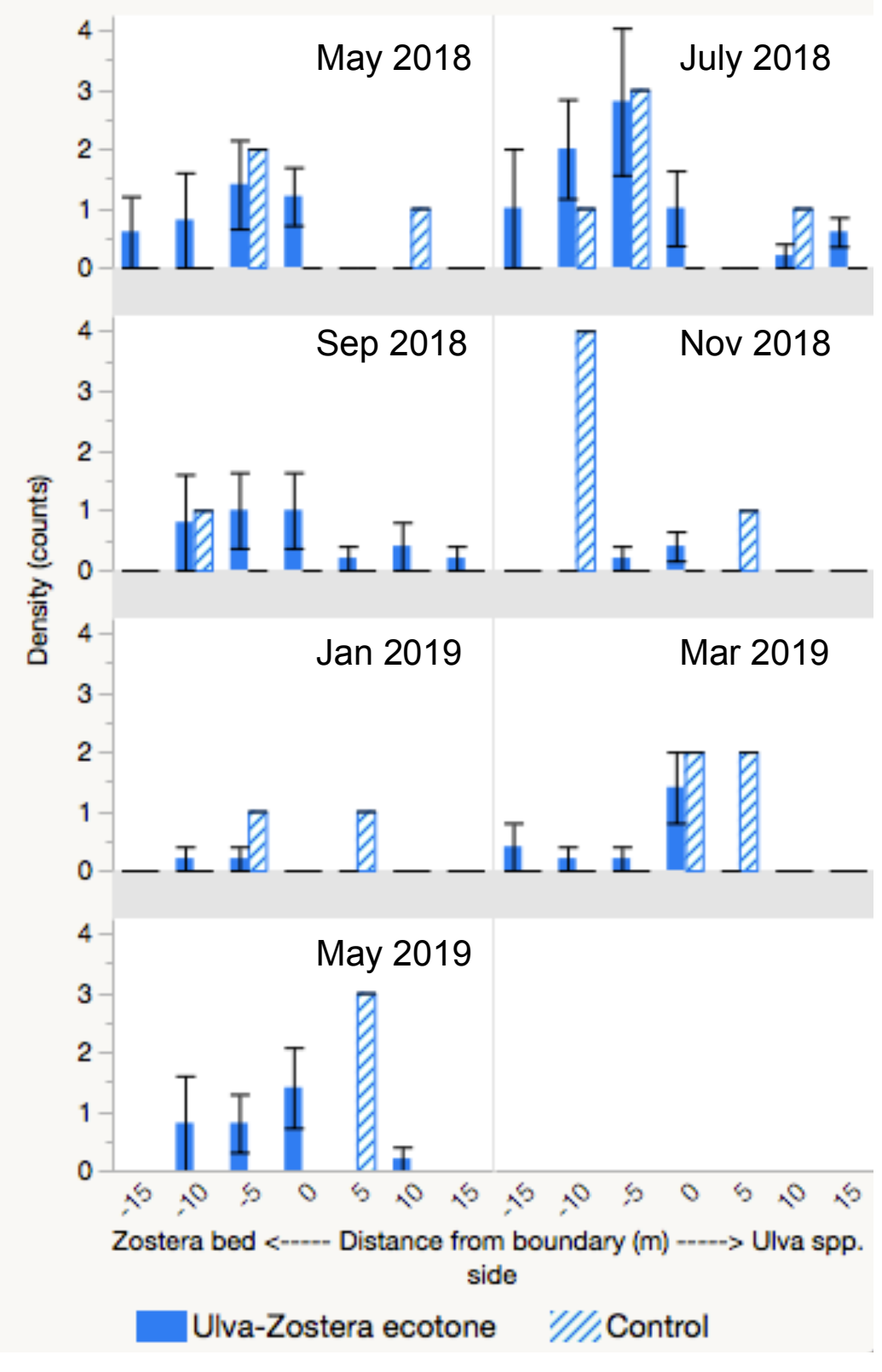

Figure 19. Density of large mesograzers across the ecotone. Filled bars represent large mesograzer density across the Ulva-Zostera ecotone $(\mathrm{N}=245)$. Error bars represent standard error of the mean due to variability between transects. Bars with diagonal lines represent large mesograzer density across the control $(\mathrm{N}=49)$. 
The relative abundance of some common large mesograzer groups varied spatially and seasonally across the ecotone. Sea slugs (Fig. 20; two-way ANOVA, Distance: $F_{6,196}=4.97, p<0.0001$, Season: $F_{6,196}=2.52, p=0.0223$, Distance $\times$ Season: $F_{36,196}=0.72, p=0.8762$ ) and isopods (Fig. 20; two-way ANOVA, Distance: $F_{6,196}=5.09, p<0.0001$, Season: $F_{6,196}=0.4350, p=0.8549$, Distance $x$ Season: $F_{36,196}=0.92, p=0.6096$ ) appeared to be more abundant at the boundary and inside the eelgrass bed than in the Ulva spp. side. On the other hand, crabs (Fig. 20; two-way ANOVA, Distance: $F_{6,196}=2.35, p=0.0322$, Season: $F_{6,196}=3.03, p=0.0074$, Distance $x$ Season: $\left.F_{36,196}=2.92, p<0.0001\right)$ were more abundant in the Ulva spp. side, and sea snails (Fig. 20; two-way ANOVA, Distance: $F_{6,196}=1.47, p=0.1914$, Season: $F_{6,196}=1.18, p=0.3185$, Distance $x$ Season: $F_{36,196}=F_{36,196}=0.65, p=0.9355$ ) were proportionally equally abundant across the ecotone. There were significant seasonal changes in relative abundance of sea slugs, with higher abundance in the spring and summer months. Density of crabs also changed seasonally, and no crabs were seen during the winter months. On the other hand, relative abundance of isopods and sea snails did not change throughout the year. Spatial patterns observed in relative abundance of sea slugs, isopods, and sea snails did not differ throughout the year. Spatial patterns detected in relative abundance of crabs were not consistent through time, with increases in density further from the ecotone boundary being stronger in the summer than other seasons. 

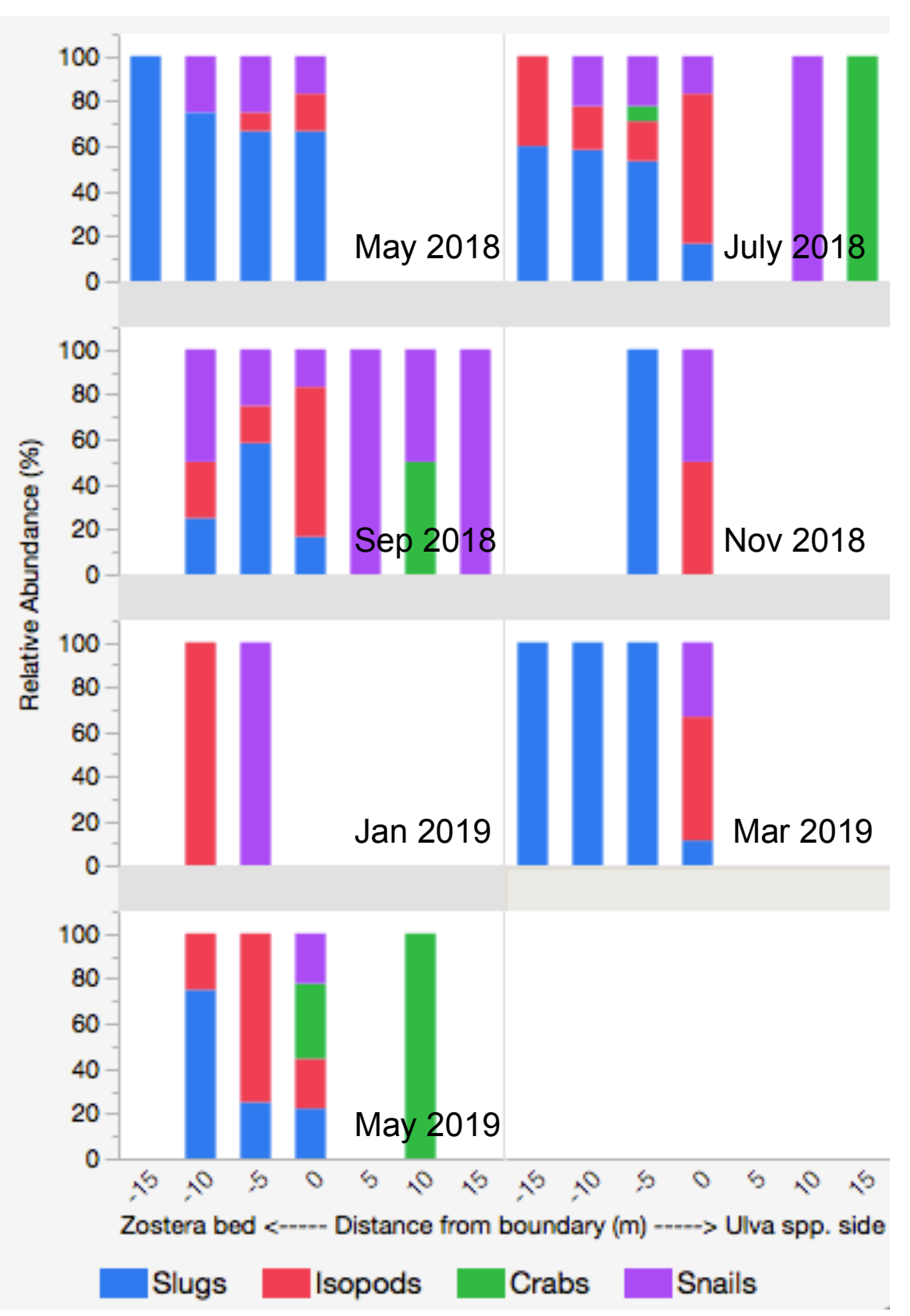

Figure 20. Relative abundance of common large $(>1 \mathrm{~cm})$ mesograzers across the ecotone. Data shown represents mean percentage of sea slugs (blue), isopods (red), crabs (green) and sea snails (purple) relative to total large mesograzer density at each mark of the transect. 
There was a significant relationship between small grazer biomass and percent cover of Ulva spp. on the pipes two weeks after being transplanted (Fig. 21; Linear Regression, $F_{1,163}=5.18, p=0.0243, R^{2}=0.03$ ), although it does not explain much variability. Ulva spp. cover was also negatively correlated with large mesograzer density (Fig. 22; Linear Regression, $F_{1,163}=6.37, p=0.0126$, $\left.R^{2}=0.04\right)$. More specifically, there was a significant relationship between percent cover of Ulva spp. and density of sea slugs (Fig. 23; Linear Regression, $\left.F_{1,163}=5.17, p=0.0243, R^{2}=0.03\right)$. This correlation was strongest in spring and summer, and was no longer significant after November 2018.

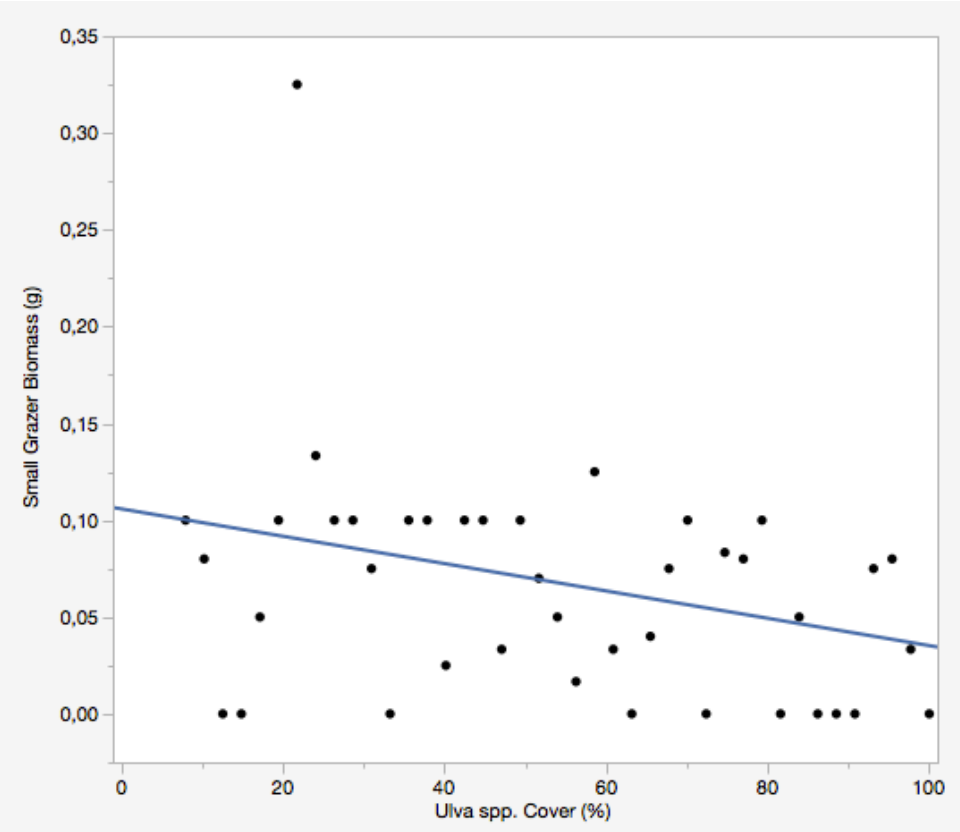

Figure 21. Correlation between small grazer biomass and Ulva spp. percent cover on transplants across the ecotone. Small grazer biomass is measured in grams and Ulva spp. cover in percentages $(\mathrm{N}=165)$. The blue line represents the best-fit line $(y=0.1059-0.0007 x)$. 


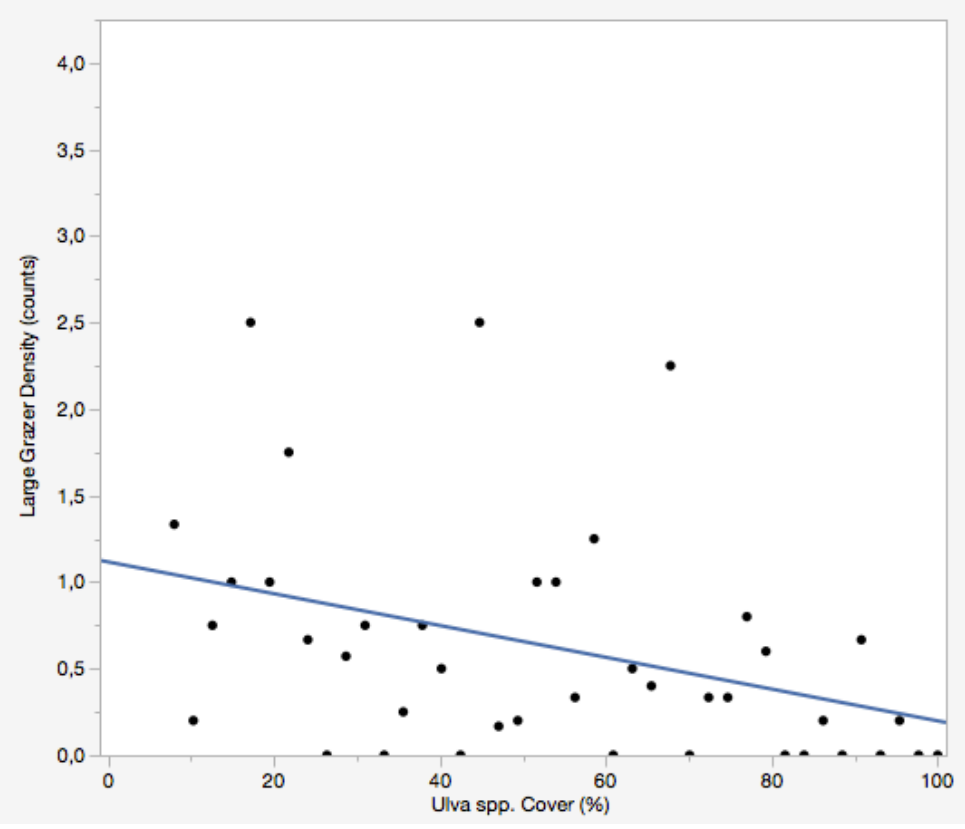

Figure 22. Correlation between large mesograzer density and Ulva spp. percent cover on transplants across the ecotone. Large grazer density is measured in counts and Ulva spp. cover in percentages $(\mathrm{N}=165)$. The blue line represents the best-fit line $(y=1.1174-0.0091 x)$.

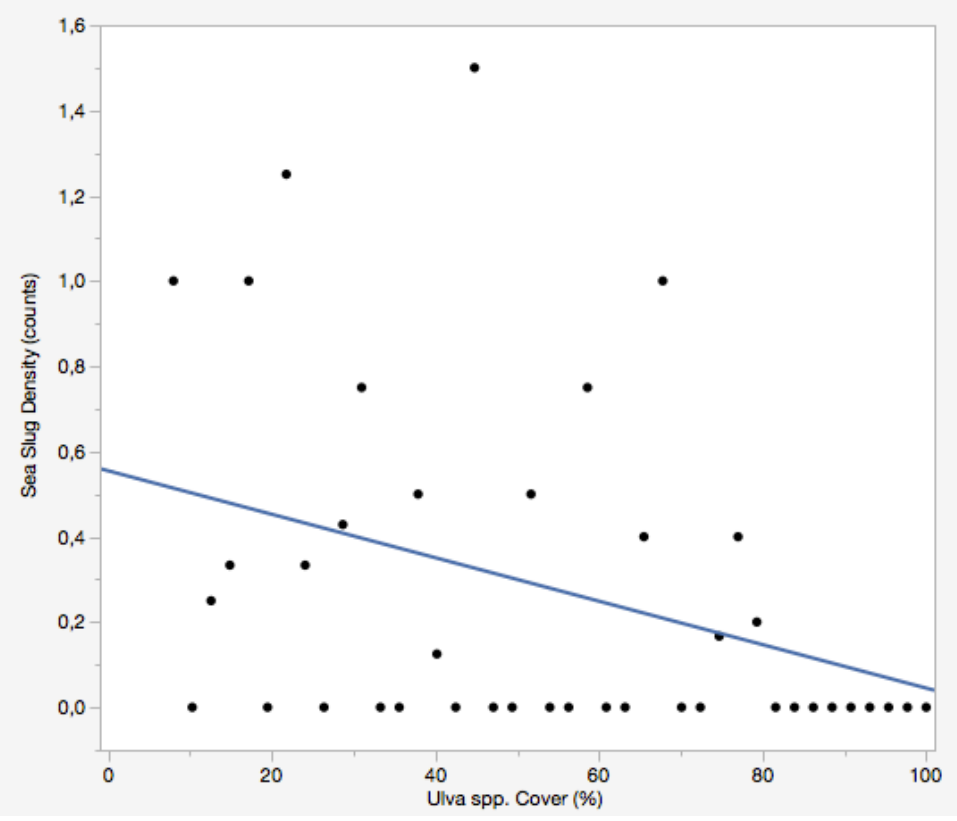

Figure 23. Regulating function of sea slugs in the eelgrass bed. Correlation between abundance of sea slugs and Ulva spp. cover on transplants across the ecotone $(N=245)$. The blue line represents the best-fit line $(y=0.5551-0.0051 x)$. 


\section{DISCUSSION}

This study described the Ulva-Zostera ecotone in Elkhorn Slough as a fairly stable feature that does not exhibit conspicuous seasonal changes. Ecotone dynamics were correlated with the biological and ecological traits of the habitatforming species on either side of the boundary. The distribution of Zostera marina was likely limited by its tolerance to desiccation (Boese et al. 2003), which sets the upper limit of the eelgrass bed and the ecotone boundary. Zostera distribution appeared resilient to external processes associated with changes in the ecology of Ulva spp., possibly because Zostera is a slow-growing perennial species with a longer life span than Ulva spp (Kautsky 1988, Lyons 2014). On

the other hand, Ulva spp. was extremely responsive to changing environmental conditions and mechanisms associated with other macrophytes (Schaadt 2005, Teichberg 2010). As a result, ecotone dynamics in Elkhorn Slough were driven by seasonality of U/va spp.

Hessing-Lewis (2011) also found very low eelgrass variability that did not show response to high fluctuations in macroalgal production in two West Coast estuaries. She suggested that macroalgal blooms might have negative effects on eelgrass at large scales, but eelgrass is not affected by macroalgae within particular estuaries. Ultimately, Hessing-Lewis (2011) concluded that eelgrass density is more strongly affected by climate and nutrient loading than changes in the abundance of macroalgal taxa. 
There appears to be an interaction between Ulva spp. and Zostera marina where their distributions overlapped at Seal Bend. The presence of Zostera marina may indirectly limit the distribution of Ulva spp. via modification of the environment, resulting in bottom-up controls on macroalgae (van Wesenbeeck et al. 2007). Ulva spp. is a morphologically plastic opportunistic species tolerant to a very wide range of environmental conditions (Valiela 1997), which allows its proliferation in diverse coastal areas around the globe (Teichberg 2010). Ulva spp. is also responsible for algal blooms that often have a negative effect on ecosystem health and productivity (Lyons 2014). For this reason, recent research studies have focused on identifying and quantifying the factors that facilitate these blooms (e.g. Teichberg et al. 2010, Hessing-Lewis et al. 2015) and have given little attention to factors that are responsible for limiting its growth. In Elkhorn Slough, the distribution of the species across the Ulva-Zostera ecotone might be influenced by processes taking place in its microscopic life stages.

Transplanted two week-old Ulva spp. had the ability to survive in the Zostera bed, yet Ulva spp. zoospores failed to recruit to that side of the ecotone (Fig. 14). This discrepancy can be explained by processes associated with microscopic life stages, such as the inability of zoospores to settle or develop (Fredesdorf 2009). Early life stages are more vulnerable to environmental stressors, with vulnerability being a factor of age, size, and time (Vadas et al. 1992). Early developmental stages of macroalgae, and especially post-settlement stages, have high mortality rates (Underwood \& Fairweather, 1989). Spores and 
germlings lack resistance mechanisms found in adults, which makes them delicate structures, critical to the macroalgal life cycle (Lubchenco 1983). It has been shown for a wide range of species that microscopic zoospores are more sensitive than adult macroscopic sporophytes to extreme abiotic conditions (Fredesdorf 2009). This is also true for bloom-forming macroalgae, where spores have experimentally shown a greater sensitivity than adult stages to both abiotic and biotic factors (Loetze et al. 1999). These differences are due to several mechanisms that might also be responsible for seasonal variations in abundance of Ulva spp. in temperate estuaries (Sousa et al. 2007). The key processes that can suppress macroalgal recruitment are physical stress, competition, grazing, or a combination of these (Vadas et al. 1992). Settlement of Ulva spp. zoospores is influenced by biological, physico-chemical and topographic conditions that vary among species (Callow et al. 2000). Ulva spp. seem to prefer rough, fine granulated substrata to smooth surfaces (Luther 1976, Fletcher and Callow 1992). Although most studies have focused on the relationship between surface characteristics and Ulva spp. spore attachment for anti-fouling recommendations (e.g. Hoipkemeier-Wilson et al. 2004, Martinelli et al. 2016), there is evidence that nutrient availability is a major factor influencing development of Ulva spp. spores (Sousa 2007).

Porewater nutrient concentrations can affect spore development, especially if concentrations of toxic pollutants are high or conditions are hypoxic (Devinny and Volse 1978). Macroalgal spores can be chemotactically drawn to nutrients that 
stimulate gametophytic growth and reproduction, but in eutrophic systems excess nutrients have indirect negative effects on development for most species (Coehlo 2000). These impacts on early life stages include the inhibition of sperm motility, fertilization, and embryo development, which results in high mortality rates (Coehlo 2000). The opposite effect is commonly observed in Ulva spp. and other opportunistic species, which have vegetative life cycles and thus are not affected by hormones-like molecules in the water that could otherwise inhibit sporulation (Coehlo 2000). Ulva intestinalis zoospores have been shown to be more sensitive to changes in external nutrient concentration than sporophytes, and to limited phosphate and excess ammonium in particular (Sousa et al. 2007). Regardless of salinity and light levels, recruitment is usually enhanced with phosphate enrichment and hindered by ammonium enrichment (Sousa et al. 2007). My data show lower phosphate and greater ammonium concentrations on the Zostera marina side of the ecotone, where Ulva spp. failed to recruit, possibly due to excretion of ammonia by organisms living in the eelgrass bed (Weihrauch and Allen 2018). Phosphate values were as high as $490 \mu \mathrm{M}$, which is above the $100 \mu \mathrm{M}$ threshold value after which spore growth is hindered for many UIva species (Sousa et al. 2007). This suggests that porewater nutrient concentrations, and specifically ammonium concentrations, had an influence on recruitment success of Ulva spp. across the ecotone.

Sediment characteristics have also been reported as important factors affecting macroalgal recruitment (Devinny and Volse 1978). Macroalgal 
recuitment via sexual reproduction is generally unsuccessful in environments where less-consoliated sediments predominate (Park and Hwang 2010). Under eutrophic conditions, increased sedimentation negatively impacts recruitment by reducing the substratum available, and preventing firm adhesion of the spores, which prevents settlement and growth of early stages (Coehlo 2000). Germination success of Ulva spp. zoospores decreases with decreasing particles size (Schories 1995, Park and Hwang 2010). At Seal Bend, larger grain sizes were observed inside the eelgrass bed than at the boundary or on the Ulva spp. side. These differences could be due to hydraulic sorting, if larger grain sizes were found towards the center of the channel, where there is higher depositional energy (Tanner 1991, Lario et al. 2002). However, the bivariate plot (Figure 12B) shows there is likely another explanation for the particle size distribution, since the majority of the larger particles fall where there is lower depositional energy, which invalidates the hydraulic sorting theory (Lario et al. 2002). Scouring due to more wave action could damage spores and gametophytes, as well as attenuate light and result in high Ulva spp. mortality (Coehlo 2000). Abrasion by movement of shoots on the eelgrass bed might also have a negative effect on Ulva spp. (Devinny and Volse 1978).

Grazing pressure is often the main factor controlling populations of opportunistic algal species (Lotze 1998). Species like Ulva spp. are especially vulnerable to grazing due to their lack of investment in chemical or structural defenses (Littler and Littler 1980). Consequently, they are a potential food source 
for a wide variety of herbivores, including mesograzers without complex feeding structures. In addition to this, specialized grazers might change their preference if they have access to a less-defended alternative food source (Goecker 2003). For instance, amphipods and isopods have a preference for green filamentous algae even though they have strong mandibles for chewing tougher, morphologically defended species (Hickman 1967, Goecker 2003). On the other hand, nutrients generated by certain grazers have been reported to stimulate algal blooms (Porter 1976). Nutrient enrichment, along with other ecophysiological constrains and algal epiphyte consumption by grazers, cause grazing to have a noncontrolling impact in certain environments (Kamermans et al. 2002, Goecker 2003).

Under eutrophic conditions, higher grazing pressure can result in a substantial loss of recruits for macroalgal populations (Coehlo 2000). In this study, the greatest density of grazers occurred where Ulva spp. had no recruitment success and transplanted Ulva spp. resulted in the lowest pecent cover. Sea slug density in particular was significantly correlated with percent cover of Ulva spp. More than $90 \%$ of the individuals within this taxonomic group were of the species Phyllaplysia taylori (Taylor's sea hare), which was found almost exclusively on eelgrass (Hughes 2018). This highlights that Ulva spp. abundance might be regulated in Zostera marina habitat via top-down control by grazers that associate strongly with Zostera. Lotze (1998) found that germination and growth of $U$. intestinalis germlings decreased by approximately $96 \%$ in the 
presence of crustacean mesograzers, and concluded that grazer presence plays a decisive role in regulating mass developments of early life stages. While grazer abundances could not explain much of the variability $\left(R^{2}=0.03\right)$ in percent cover of Ulva spp. on transplants across the Ulva-Zostera ecotone, there was a strong correlation between grazer abundance and recruitment success of Ulva spp., suggesting that grazers regulate Ulva spp. recruitment at its early life stages.

Approximately $50-75 \%$ of the Elkhorn Slough water volume is flushed in and out of the estuary with each tidal cycle (Malzone 1999). Therefore, water quality parameters are not likely to affect the distribution of macrophytes across the ecotone. In opportunistic green macroalgae like Ulva spp., spore development and growth is strongly dependent on salinity (Sousa 2007). Ulva spp. spore recruitment is strongly constrained in salinities lower than 20ppt (Sousa 2007). Even though there were spatial differences in temperature (Figure 5), salinity (Figure 6), pH (Figure 7), and dissolved oxygen (Figure 8), all measurements were well within Ulva spp.'s tolerance range (Kjeldsen and Phinney 1972), and cannot explain why the macroalga was absent inside the eelgrass bed. Nutrient concentrations in surface water were very similar to those reported in a nearby site as part of the National Estuarine Research Reserve System (NERRS)'s water quality monitoring program (Elkhorn Slough Foundation). Again, no anomalies or extreme values were found outside of the usual fluctuations between dry and wet seasons. 
Competition for light was predicted to be a key factor preventing the expansion of Ulva spp. to the Zostera marina side (Sand-Jensen 1988). However, the percent length down to which Ulva spp. survival was observed on ropes in the transplant experiments did not vary with eelgrass density (Figure 17). Determining how Ulva spp. recruitment is affected by light as an independent factor is a difficult task, since this correlation seems to strongly depend on a set of environmental factors (Sousa 2007). Light can be a relevant factor if paired with availability of nutrients and hydrodynamics of the estuarine system (Martins et al., 2001). Ulva spp. spores have been reported to survive more than 10 months (Schories 1995) and germinate (Santelices et al. 2002) in total darkness. These results suggest that there was enough light available throughout the water column at all distances from the boundary within the eelgrass bed, and that light does not affect the spatial distribution of Ulva spp. across the Ulva-Zostera ecotone in Elkhorn Slough. On the other hand, seasonal variability in macroalgal abundance can be attributed to lower hydrodynamics in the spring and summer that result in lower turbidity and more light available in the water column (Cardoso et al. 2004). These conditions favored the increase in Ulva spp. abundance during the spring and summer months relative to the fall and winter months.

Previous studies reported lower affinity of macroalgal zoospores for unstable substrates with highly heterogeneous particle composition (Devinny and Volse 1978). These studies reported a relationship between sediment composition and 
zoospore attachment in certain brown seaweeds exclusively (Lotze 1998). Park and Hwang (2011) described a relationship between density of Ulva spp. and ratio of sand to silt in the sediment. No differences in ecology of Ulva spp. across sediments with differing particle heterogeneity have been described on muddy substrates with grain size variances as small as found in our study. Sediment characteristics had limited effect on Ulva spp. in our study system, as there were no spatial or seasonal differences in particle heterogeneity across the ecotone (Figure 13). Thus, particle heterogeneity can also be ruled out as a relevant factor limiting Ulva spp. distribution in Seal Bend.

While the Ulva-Zostera ecotone in Elkhorn Slough meets the traditional definition of an ecotone (Attrill 2002), its spatial and seasonal dynamics are not driven by direct interspecific interactions as are implied in recent revisions of the ecotone concept. Changes in macrophyte abundance and distribution, and consequently the overall system ecology, seem to depend on spatial limitations in the distribution of Ulva spp. and seasonal fluctuations in the abundance of Ulva spp. Therefore, shedding light on the factors limiting the distribution of Ulva spp. and their relative importance is crucial to understanding the system as a whole. This study points to a combination of abiotic and biotic factors driving the Ulva-Zostera ecotone. More specifically, the presence of Zostera marina at Seal Bend has resulted in modified biogeochemical conditions that negatively impact settlement and development of Ulva spp. 
Zostera marina was historically very abundant in Elkhorn Slough, but started declining in the 1920's (Van Dyke and Wasson 2005). In recent decades, the population has been rapidly recovering as a consequence of increased tidal flows within the slough (Broenkow and Breaker 2005), and increased sea otter density and foraging (Hughes 2013). In the lower slough region, Zostera marina has recovered approximately $100,000 \mathrm{~m}^{2}$ of land (Zimmerman and Caffrey, 2002). During the last sampling period of this study (May 2019), an isolated patch of eelgrass was observed for the first time among the Ulva spp. mats in the control transect. This sighting highlights Zostera marina's potential for rapid growth and expansion in Elkhorn Slough, a rare example of seagrass recovery in a highly eutrophied system (Grant 2009). At Seal Bend, eelgrass beds appear to have expanded to their tidal limit where dessication stress occurs. It is possible that Ulva spp. occurred deeper when Zostera marina was not present, and that the ecotone boundary has shifter to shallower waters with the recent recovery of Zostera.

The mechanisms associated with survival of early macroalgal developmental stages are understudied compared to those affecting adult individuals, but have been shown to be just as, if not more important (Vadas et al. 1992). Studies addressing production, development, growth and survival of early stages have focused on brown algae, and neglected mass-occurring filamentous algal groups like Ulva spp. In order to have a greater understanding of the key processes having an effect on the ecology of bloom-forming macroalgae, more research 
needs to be conducted on the population dynamics of all life history stages. This study suggests that factors affecting microscopic stages of macroalgae might have a greater influence on species distribution than previously thought.

Abiotic and biotic factors limitting the distribution of Ulva spp. in Elkhorn Slough play an essential role in maintaining biodiversity of the ecosystem. These constraining factors associated with Zostera marina prevent the proliferation and overgrowth of Ulva spp., otherwise likely to predominate seasonally in shallow areas of the estuary due to its opportunistic nature. The presence of ecotones among multiple habitat-forming species translates into higher faunal diversity even at small scales, and an overall healthier system. For this reason, eelgrass meadows provide an additional ecosystem service by biomechanically modifying environmental conditions and ultimately limiting the spread of Ulva spp. Their ecological role in Elkhorn Slough is likely to become even more important with the effects of climate change, since conditions will be more favorable for the proliferation of opportunistic ephemeral macroalgae as a consequence of higher temperatures, large shifts in coastal productivity, and higher nutrient input.

The ecological value of ecotones as critical habitats, controls of nutrients and water flow, and indicators of environmental change at a global scale are well known. Management of these habitat boundaries requires a deeper understanding of their underlying ecological processes, along with informed predictions about the impact different management strategies might have on these processes. Ecotones are arguably a delicate balance of interacting abiotic 
and biotic patterns, and are therefore considered indicators of widespread changes that can be helpful to predict the large-scale effects of climate change on ecosystem structure and functioning. In order to decide on the most appropriate management and conservation strategies, there is a need for more local research studies from a wide variety of ecotones. 


\section{LITERATURE CITED}

Allen, T.F.H. \& Starr, T.B. 1982. Hierarchy: perspectivesfor ecological complexity. Univ. Chicago, Chicago, Illinois, USA.

Angelini, C., Altieri, A.H., Silliman, B.R. \& Bertness, M.D. 2011. Interactions among foundation species and their consequences for community organization, biodiversity, and conservation. Bioscience. 61:782-9.

Ansell, A., Gibson, R., Barnes, M. \& Press, U. 1998. Ecological impact of green macroalgal blooms. Oceanogr. Mar. Biol. An Annu. Rev. 36:97-125.

Attrill, M.J. \& Rundle, S.D. 2002. Ecotone or ecocline: ecological boundaries in estuaries. Estuar. Coast. Shelf Sci. 55:929-36.

Augustin, L.N., Irish, J.L. \& Lynett, P. 2009. Laboratory and numerical studies of wave damping by emergent and near-emergent wetland vegetation. Coast. Eng. 56:332-40.

Barko, J.W. \& Smart, R.M. 1986. Sediment-related mechanisms of growth limitation in submersed macrophytes. Ecology. 67:1328-40.

Bassett, R. 2010. Quantifying spatially-explicit change in sediment storage on an emerging floodplain and wetland on Carneros Creek, CA. Capstone Project (CSUMB).

Bell, S.S. \& Hall, M.O. 1997. Drift macroalgal abundance in seagrass beds: investigating large-scale associations with physical and biotic attributes. Mar. Ecol. Prog. Ser. 147:277-83.

Boese, B.L., Alayan, K.E., Gooch, E.F. \& Robbins, B.D. 2003. Desiccation index: a measure of damage caused by adverse aerial exposure on intertidal eelgrass (Zostera marina) in an Oregon (USA) estuary. Aquat. Bot. 76:32937.

Boström, C., Baden, S., Bockelmann, A., Dromph, K., Fredriksen, S., Gustafsson, C., Krause-Jensen, D. et al. 2014. Distribution, structure and function of Nordic eelgrass (Zostera marina) ecosystems: implications for coastal management and conservation. Aquat. Conserv. Mar. Freshw. Ecosyst. 24:410-34.

Boström, C. \& Bonsdorff, E. 2000. Zoobenthic community establishment and habitat complexity the importance of seagrass shoot-density, morphology 
and physical disturbance for faunal recruitment. Mar. Ecol. Prog. Ser. 205:123-38.

Boström, C., Pittman, S.J. \& Simenstad, C. 2017. Ecological consequences of seagrass and salt-marsh seascape patterning on marine fauna. In Pittman, S.J. [Eds.] Seascape Ecology. Wiley-Blackwell, Hoboken, NJ, pp. 121-153.

Bouma, T.J., De Vries, M.B., Low, E., Peralta, G., Tánczos, I.V., van de Koppel, J. \& Herman, P.M.J. 2005. Trade-offs related to ecosystem engineering: A case study on stiffness of emerging macrophytes. Ecology 86:2187-99.

Broenkow, W.W. \& Breaker, L. 2005. A 30-year history of tide and current measurements in Elkhorn Slough, California. MLML Tech. Rep.

Caffrey, J.M. 2002. Changes in a California estuary: a profile of Elkhorn Slough. Elkhorn Slough Foundation.

Callow, M.E., Callow, J.A., Ista, L.K., Coleman, S.E., Nolasco, A.C. \& Lopez, G.P. 2000. Use of self-assembled monolayers of different wettabilities to study surface selection and primary adhesion processes of green algal (Enteromorpha) zoospores. Appl. Environ. Microbiol. 66:3249-54.

Campbell, J.E. \& Fourqurean, J.W. 2014. Ocean acidification outweighs nutrient effects in structuring seagrass epiphyte communities. J. Ecol. 102:730-7.

Cardoso, P.G., Pardal, M.A., Raffaelli, D., Baeta, A. \& Marques, J.C. 2004. Macroinvertebrate response to different species of macroalgal mats and the role of disturbance history. J. Exp. Mar. Bio. Ecol. 308:207-20.

Carruthers, T.J.B., Longstaff, B.J., Dennison, W.C., Abal, E.G. \& Aioi, K. 2001. Measurement of light penetration in relation to seagrass. Glob. seagrass Res. methods. Elsevier, Amsterdam. 369-92.

Chapin, T.P., Caffrey, J.M., Jannasch, H.W., Coletti, L.J., Haskins, J.C. \& Johnson, K.S. 2004. Nitrate sources and sinks in Elkhorn Slough, California: Results from long-term continuous in situ nitrate analyzers. Estuaries 27:882-94.

Chave, J. 2013. The problem of pattern and scale in ecology: what have we learned in 20 years? Ecol. Lett. 16:4-16.

Clements, F.E. 1905. Research methods in ecology. The University Publishing Company, Lincoln, NE., 334 pp. 
Coelho, S.M., Rijstenbil, J.W. \& Brown, M.T. 2000. Impacts of anthropogenic stresses on the early development stages of seaweeds. J. Aquat. Ecosyst. Stress Recover. 7:317-33.

Connell, S.D. \& Russell, B.D. 2010. The direct effects of increasing CO2 and temperature on non-calcifying organisms: increasing the potential for phase shifts in kelp forests. Proc. R. Soc. B Biol. Sci. 277:1409-15.

Costanza, R., d'Arge, R., De Groot, R., Farber, S., Grasso, M., Hannon, B., Limburg, K. et al. 1997. The value of the world's ecosystem services and natural capital. Nature 387:253.

Deegan, L.A., Wright, A., Ayvazian, S.G., Finn, J.T., Golden, H., Merson, R.R. \& Harrison, J. 2002. Nitrogen loading alters seagrass ecosystem structure and support of higher trophic levels. Aquat. Conserv. Mar. Freshw. Ecosyst. 12:193-212.

Delcourt, P.A. \& Delcourt, H.R. 1992. Ecotone dynamics in space and time. In Landscape Boundaries. Springer, pp. 19-54.

Devinny, J.S. \& Volse, L.A. 1978. Effects of sediments on the development of Macrocystis pyrifera gametophytes. Mar. Biol. 48:343-8.

Ebling, F.J., Sleigh, M.A., Sloane, J.F. \& Kitching, J.A. 1960. The ecology of Lough Ine: VII. Distribution of some common plants and animals of the littoral and shallow sublittoral regions. J. Ecol. 29-53.

Eriksson, B.K. \& Johansson, G. 2005. Effects of sedimentation on macroalgae: species-specific responses are related to reproductive traits. Oecologia. 143:438-48.

Filbee-Dexter, K. \& Scheibling, R.E. 2012. Hurricane-mediated defoliation of kelp beds and pulsed delivery of kelp detritus to offshore sedimentary habitats. Mar. Ecol. Prog. Ser. 455:51-64.

Fletcher, R.L. \& Callow, M.E. 1992. The settlement, attachment and establishment of marine algal spores. Br. Phycol. J. 27:303-29.

Fletcher, R. \& Fortin, M.-J. 2018. Introduction to Spatial Ecology and Its Relevance for Conservation. In Spatial Ecology and Conservation Modeling. Springer, pp. 1-13.

Forman, R.T.T. \& Godron, M. 1986. Landscape ecology. John Wiley \& Sons, New York, 620 pp. 
Fortin, M.-J. \& Dale, M.R.T. 2005. Spatial analysis: a guide for ecologists. Cambridge University Press.

Fredersdorf, J., Müller, R., Becker, S., Wiencke, C. \& Bischof, K. 2009. Interactive effects of radiation, temperature and salinity on different life history stages of the Arctic kelp Alaria esculenta (Phaeophyceae). Oecologia. 160:483-92.

Gao, Y., Fang, J., Zhang, J., Ren, L., Mao, Y., Li, B., Zhang, M. et al. 2011. The impact of the herbicide atrazine on growth and photosynthesis of seagrass, Zostera marina (L.), seedlings. Mar. Pollut. Bull. 62:1628-31.

Goecker, M.E. \& Kåll, S.E. 2003. Grazing preferences of marine isopods and amphipods on three prominent algal species of the Baltic Sea. J. Sea Res. 50:309-14.

Gosz, J.R. 1993. Ecotone Hierarchies Author ( s ): James R . Gosz Published by : Wiley on behalf of the Ecological Society of America Stable URL: http://www.jstor.org/stable/1941905 Wiley, Ecological Society of America are collaborating with JSTOR to digitize, preserve. 3:369-76.

Graham, M.H. 2004. Effects of local deforestation on the diversity and structure of southern California giant kelp forest food webs. Ecosystems 7:341-57.

Graham, M.H., Fox, M.D. \& Hamilton, S.L. 2016. Macrophyte productivity and the provisioning of energy and habitat to nearshore systems. In Ólafsson, E. [Eds.] Marine macrophytes as foundation species. CRC Press, Boca Raton, FL, pp. 133-160.

Grant, N.E. 2009. Changes in cover and use of Zostera marina habitat in Elkhorn Slough, California.

Green, L. \& Fong, P. 2016. The good, the bad and the Ulva: the density dependent role of macroalgal subsidies in influencing diversity and trophic structure of an estuarine community. Oikos. 125:988-1000.

Hansen, A.J., di Castri, F. \& Naiman, R.J. 1988. Ecotones: what and why. Biol. Int. 17:9-46.

Hansen, A.J., Risser, P.G. \& di Castri, F. 1992. Epilogue: biodiversity and ecological flows across ecotones. In Landscape Boundaries. Springer, pp. 423-38. 
Hauxwell, J., Cebrián, J., Furlong, C. \& Valiela, I. 2001. Macroalgal canopies contribute to eelgrass (Zostera marina) decline in temperate estuarine ecosystems. Ecology 82:1007-22.

Hessing-Lewis, M.L., Hacker, S.D., Menge, B.A. \& Rumrill, S.S. 2011. Contextdependent eelgrass-macroalgae interactions along an estuarine gradient in the Pacific Northwest, USA. Estuaries and Coasts 34:1169-81.

Hickman, C.P. 1967. Biology of the Invertebrates: Saint Louis. The CV Mosby Company, Maryland Heights, MO., 673 pp.

Hillebrand, H. 2004. On the generality of the latitudinal diversity gradient. Am. Nat. 163:192-211.

Hoipkemeier-Wilson, L., Schumacher, J.F., Carman, M.L., Gibson, A.L., Feinberg, A.W., Callow, M.E., Finlay, J.A. et al. 2004. Antifouling potential of lubricious, micro-engineered, PDMS elastomers against zoospores of the green fouling alga Ulva (Enteromorpha). Biofouling. 20:53-63.

Holland, M. 2012. Ecotones: the role of landscape boundaries in the management and restoration of changing environments. Springer Science \& Business Media, Berlin, 166 pp.

Hughes, B.B., Eby, R., Van Dyke, E., Tinker, M.T., Marks, C.I., Johnson, K.S. \& Wasson, K. 2013. Recovery of a top predator mediates negative eutrophic effects on seagrass. Proc. Natl. Acad. Sci. 110:15313-8.

Hughes, B.B., Hammerstrom, K.K., Grant, N.E., Hoshijima, U., Eby, R. \& Wasson, K. 2016. Trophic cascades on the edge: fostering seagrass resilience via a novel pathway. Oecologia. 182:231-41.

Hughes, B.B., Lummis, S.C., Anderson, S.C. \& Kroeker, K.J. 2018. Unexpected resilience of a seagrass system exposed to global stressors. Glob. Chang. Biol. 24:224-34.

Janauer, G.A. \& Kum, G. 1996. Macrophytes and flood plain water dynamics in the River Danube ecotone research region (Austria). Hydrobiologia. 340:137-40.

Janauer, G.A. 2001. Is what has been measured of any direct relevance to the success of the macrophyte in its particular environment? J. Limnol. 60: 3338. 
Jeltsch, F., Moloney, K. \& Milton, S.J. 1999. Detecting process from snapshot pattern: lessons from tree spacing in the southern Kalahari. Oikos. 451-66.

Kamermans, P., Malta, E.-J., Verschuure, J.M., Schrijvers, L., Lentz, L.F. \& Lien, A.T.A. 2002. Effect of grazing by isopods and amphipods on growth of Ulva spp. (Chlorophyta). Aquat. Ecol. 36:425-33.

Kark, S. \& van Rensburg, B.J. 2006. Ecotones: marginal or central areas of transition? Isr. J. Ecol. Evol. 52:29-53.

Kautsky, L. 1988. Life strategies of aquatic soft bottom macrophytes. Oikos $126-$ 35.

Kjeldsen, C.K. \& Phinney, H.K. 1972. Effects of variations in salinity and temperature on some estuarine macro-algae. In Proc 7th Int Seaweed Symp. University of Toleyo Press, Tokyo. pp. 301-8.

Kleiber, M. 1947. Body size and metabolic rate. Physiol. Rev. 27:511-41.

Lapointe, B.E., Littler, M.M. \& Littler, D.S. 1992. Nutrient availability to marine macroalgae in siliciclastic versus carbonate-rich coastal waters. Estuaries 15:75-82.

Lario, J., Spencer, C., Plater, A.J., Zazo, C., Goy, J.L. \& Dabrio, C.J. 2002. Particle size characterisation of Holocene back-barrier sequences from North Atlantic coasts (SW Spain and SE England). Geomorphology. 42:2542.

Leoni, V., Vela, A., Pasqualini, V., Pergent-Martini, C. \& Pergent, G. 2008. Effects of experimental reduction of light and nutrient enrichments ( $N$ and $P$ ) on seagrasses: a review. Aquat. Conserv. Mar. Freshw. Ecosyst. 18:202-20.

Levin, S.A. 1992. The problem of pattern and scale in ecology: the Robert $\mathrm{H}$. MacArthur award lecture. Ecology 73:1943-67.

Lilly, S.J., Sloane, J.F., Bassindale, R., Ebling, F.J. \& Kitching, J.A. 1953. The ecology of the Lough Ine rapids with special reference to water currents. $J$. Anim. Acology. 87-122.

Littler, M.M. \& Littler, D.S. 1980. The evolution of thallus form and survival strategies in benthic marine macroalgae: field and laboratory tests of a functional form model. Am. Nat. 116:25-44. 
Livingston, B.E. 1903. The distribution of the upland plant societies of Kent County, Michigan. Bot. Gaz. 35:36-55.

Lotze, H.K., Schramm, W., Schories, D. \& Worm, B. 1999. Control of macroalgal blooms at early developmental stages: Pilayella littoralis versus Enteromorpha spp. Oecologia 119:46-54.

Lubchenco, J. 1983. Littorina and Fucus: effects of herbivores, substratum heterogeneity, and plant escapes during succession. Ecology 64:1116-23.

Luther, G. 1976. Bewuchsuntersuchungen auf Natursteinsubstraten im Gezeitenbereich des Nordsylter Wattenmeeres: Algen. Helgoländer Wissenschaftliche Meeresuntersuchungen 28:318.

Lyons, D.A., Arvanitidis, C., Blight, A.J., Chatzinikolaou, E., Guy-Haim, T., Kotta, J., Orav-Kotta, H. et al. 2014. Macroalgal blooms alter community structure and primary productivity in marine ecosystems. Glob. Chang. Biol. 20:271224.

MacArthur, R.H., Diamond, J.M. \& Karr, J.R. 1972. Density compensation in island faunas. Ecology 53:330-42.

MacKenzie Jr, C.L. 2005. Removal of sea lettuce, Ulva spp., in estuaries to improve the environments for invertebrates, fish, wading birds, and eelgrass, Zostera marina. Mar. Fish. Rev. 67:1-8.

Malzone, C.M. 1999. Tidal scour and its relation to erosion and sediment transport in Elkhorn Slough. MS Thesis, San Jose State University, 96 pp.

Martinelli, E., Hill, S.D., Finlay, J.A., Callow, M.E., Callow, J.A., Glisenti, A. \& Galli, G. 2016. Amphiphilic modified-styrene copolymer films:

Antifouling/fouling release properties against the green alga Ulva linza. Prog. Org. Coatings. 90:235-42.

Martins, I., Pardal, M.A., Lillebø, A.I., Flindt, M.R. \& Marques, J.C. 2001. Hydrodynamics as a major factor controlling the occurrence of green macroalgal blooms in a eutrophic estuary: a case study on the influence of precipitation and river management. Estuar. Coast. Shelf Sci. 52:165-77.

Maxwell, P.S., Pitt, K.A., Olds, A.D., Rissik, D. \& Connolly, R.M. 2015. Identifying habitats at risk: simple models can reveal complex ecosystem dynamics. Ecol. Appl. 25:573-87. 
McCave, I.N. \& Syvitski, J.P.M. 1991. Principles and methods of geological particle size analysis. Cambrige University Press, New York, 368 pp.

McIntire, E.J.B. \& Fajardo, A. 2009. Beyond description: the active and effective way to infer processes from spatial patterns. Ecology. 90:46-56.

McLusky, D.S. \& Elliot, M. 2004. The estuarine ecology: ecology, threats and management. Oxford University Press, UK.

Moore, K.A. \& Wetzel, R.L. 2000. Seasonal variations in eelgrass (Zostera marina L.) responses to nutrient enrichment and reduced light availability in experimental ecosystems. J. Exp. Mar. Bio. Ecol. 244:1-28.

Moritz, C. 2001. Biodiversity hotspots and beyond: the need for preserving environmental transitions. Trends Ecol. Evol. 16: 431.

Naiman, R.J. \& Decamps, H. 1990. Aquatic-terrestrial ecotones: summary and recommendations. Ecol. Manag. Aquat. Ecotones. UNESCO, Paris, Parthenon Publ. Gr. Carnforth. 295-301.

Olafsson, E. 2017. Marine Macrophytes as Foundation Species. CRC Press, Boca Raton, FL., 277 pp.

Paine, R.T. 1980. Food webs: linkage, interaction strength and community infrastructure. J. Anim. Ecol. 667-85.

Piriou, J.Y. \& Duval, V. 1990. Photosynthese et nutrition carbonée chez Ulva sp. Document DRO. EL no 90.31. IFREMER (Institut Français Rech. pour l'Exploitation la MER), BP. 70:29263.

Porter, K.G. 1976. Enhancement of algal growth and productivity by grazing zooplankton. Science 192:1332-4.

Raffaelli, D., Hull, S. \& Milne, H. 1989. Long-term changes in nutrients, weed mats and shorebirds in an estuarine system. Cah. Biol. Mar. 30:259-70.

Reusch, T.B.H. \& Hughes, A.R. 2006. The emerging role of genetic diversity for ecosystem functioning: estuarine macrophytes as models. Estuaries and Coasts 29:159-64.

Risser, P.G. 1993. Ecotones at local to regional scales from around the world. Ecol. Appl. 3:367-8. 
Rykaczewski, R.R. \& Dunne, J.P. 2010. Enhanced nutrient supply to the California Current Ecosystem with global warming and increased stratification in an earth system model. Geophys. Res. Lett. 37: L21606.

Sand-Jensen, K. 1988. Minimum light requirements for growth in Ulva lactuca. Mar. Ecol. Prog. Ser. Oldend. 50:187-93.

Santelices, B. 2002. Recent advances in fertilization ecology of macroalgae. J. Phycol. 38:4-10.

Schaadt, T.J. 2005. Patterns and causes of variability in the cover, biomass, and total abundance of Ulva spp. Elkhorn Slough, California. MS Thesis. Calif. State Univ. Monterey Bay, 74 pp.

Schiel, D.R. \& Gunn, T.D. 2019. Effects of sediment on early life history stages of habitat-dominating fucoid algae. J. Exp. Mar. Bio. Ecol. 516:44-50.

Schories, D. 1995. Sporulation of Enteromorpha spp. (Chlorophyta) and overwintering of spores in sediments of the Wadden Sea, Island Sylt, North Sea. Netherlands J. Aquat. Ecol. 29:341-7.

Short, F.T., Koch, E.W., Creed, J.C., Magalhaes, K.M., Fernandez, E. \& Gaeckle, J.L. 2006. SeagrassNet monitoring across the Americas: case studies of seagrass decline. Mar. Ecol. 27:277-89.

Silveira, M.J. 2015. The effect of habitat and sediment type on the occurrence of non-native and native species of aquatic macrophyte in subtropical regions. Biosci. J. 31.

Smith, R.E. 1973. The hydrography of Elkhorn Slough: a shallow California coastal Embayment: Annual Report, Part 2, 1973.

Sousa, A.I., Martins, I., Lillebø, A.I., Flindt, M.R. \& Pardal, M.A. 2007. Influence of salinity, nutrients and light on the germination and growth of Enteromorpha sp. spores. J. Exp. Mar. Bio. Ecol. 341:142-50.

Stevenson, R.J., Bothwell, M.L., Lowe, R.L. \& Thorp, J.H. 1996. Algal ecology: Freshwater benthic ecosystem. Academic press.

Tanner, W.F. 1991. Suite statistics: the hydrodynamic evolution of the sediment pool. Princ. methods Appl. Part. size Anal. 225-36.

Teichberg, M., Fox, S.E., Olsen, Y.S., Valiela, I., Martinetto, P., Iribarne, O., Muto, E.Y. et al. 2010. Eutrophication and macroalgal blooms in temperate 
and tropical coastal waters: nutrient enrichment experiments with Ulva spp. Glob. Chang. Biol. 16:2624-37.

Thiel, M. \& Fraser, C. 2016. The role of floating plants in dispersal of biota across habitats and ecosystems. In Ólafsson, E. [Eds.] Marine macrophytes as foundation species. CRC Press, Boca Raton, FL, pp. 76-94.

Twilley, R.R., Kemp, W.M., Staver, K.W., Stevenson, J.C. \& Boynton, W.R. 1985. Nutrient enrichment of estuarine submersed vascular plant communities. 1. Algal growth and effects on production of plants and associated communities. Mar. Ecol. Prog. Ser. Oldend. 23:179-91.

Underwood, A.J. \& Chapman, M.G. 1996. Scales of spatial patterns of distribution of intertidal invertebrates. Oecologia 107:212-24.

Underwood, A.J., Chapman, M.G. \& Connell, S.D. 2000. Observations in ecology: you can't make progress on processes without understanding the patterns. J. Exp. Mar. Bio. Ecol. 250:97-115.

Underwood, A.J. \& Fairweather, P.G. 1989. Supply-side ecology and benthic marine assemblages. Trends Ecol. Evol. 4:16-20.

Vadas Sr, R.L., Johnson, S. \& Norton, T.A. 1992. Recruitment and mortality of early post-settlement stages of benthic algae. Br. Phycol. J. 27:331-51.

Valiela, I., McClelland, J., Hauxwell, J., Behr, P.J., Hersh, D. \& Foreman, K. 1997. Macroalgal blooms in shallow estuaries: controls and ecophysiological and ecosystem consequences. Limnol. Oceanogr. 42:1105-18.

Van der Maarel, E. 1976. On the establishment of plant community boundaries. Ber. Dtsch. Bot. Ges. 89:415-43.

Van Dyke, E. \& Wasson, K. 2005. Historical ecology of a central California estuary: 150 years of habitat change. Estuaries. 28:173-89.

Van Wesenbeeck, B.K., Van de Koppel, J., Herman, P.M.J., Bakker, J.P. \& Bouma, T.J. 2007. Biomechanical warfare in ecology; negative interactions between species by habitat modification. Oikos 116:742-50.

Wang, Y., Wang, Y., Zhu, L., Zhou, B. \& Tang, X. 2012. Comparative studies on the ecophysiological differences of two green tide macroalgae under controlled laboratory conditions. PLoS One 7:e38245. 
Waycott, M., Duarte, C.M., Carruthers, T.J.B., Orth, R.J., Dennison, W.C., Olyarnik, S., Calladine, A. et al. 2009. Accelerating loss of seagrasses across the globe threatens coastal ecosystems. Proc. Natl. Acad. Sci. 106:12377-81.

Waycott, M., Procaccini, G., Les, D.H. \& Reusch, T.B.H. 2007. Seagrass evolution, ecology and conservation: a genetic perspective. In Seagrasses: Biology, Ecology and Conservation. Springer, pp. 25-50.

Worm, B., Lotze, H.K., Boström, C., Engkvist, R., Labanauskas, V. \& Sommer, U. 1999. Marine diversity shift linked to interactions among grazers, nutrients and propagule banks. Mar. Ecol. Prog. Ser. 185:309-14. 